\title{
LP-CEM: A modeling tool for power systems planning incorporating climate change effects and macroeconomic trends for New Jersey, United States
}

\author{
Shankar Chandramowli ${ }^{1}$, Frank Felder, Nancy Mantell, Will Irving and Joseph Seneca
}

Rutgers University, 33 Livingston Avenue, New Brunswick, NJ-08901

The electric power sector is highly vulnerable to climate change, yet long-term capacity expansion models often fail to take into account for it. This paper presents an overview of LP-CEM (Linear Programming based Capacity Expansion Model), which incorporates both the effects of long-term warming and the state/regional-level macroeconomic trends. We apply the modeling framework for the electric power system in New Jersey, United States. Some of the methodological advances introduced in this research are: the use of high-resolution temperature projections data in a power sector capacity expansion model; the incorporation of changes in sectoral composition of electricity demand over time; the incorporation of the effects of climate change and variability on both the demand and supply-side of power sector using parameters estimated in the literature; and an inter-model coupling link with a macroeconomic model to account for price elasticity of demand and other effects on the broader macro-economy. LP-CEM-type models can be of use to state/region-level policymakers to plan for future mitigation and adaptation policies to climate change. Scenarios with climate variability, climate change effects and with high economic growth rates result in higher capacity additions, supply costs, wholesale/retail prices and total ratepayers' costs in the next forty years.

Keywords: Climate change, electric power sector, capacity expansion model, New Jersey

\section{Introduction}

Climate change poses a serious threat to human welfare $[1,2,3]$. Some of the key environmental effects of climate change are: rise in global surface temperature, changes to hydrological cycles, ocean acidification, rise in mean sea levels and higher incidences of extreme weather events (like storm surges, heavy precipitation and heat waves) [3]. The environmental implications of climate change are especially serious for the electric power sector, which oversees a complex and inter-connected network of generation, transmission and distribution assets spread over a wide geographic area.

The motivation for incorporating climate change effects in a long-term power systems planning is grounded on three factors. First, the electric power sector is the single largest emitter of carbon dioxide $\left(\mathrm{CO}_{2}\right)$ and other pollutants like sulfur dioxide $\left(\mathrm{SO}_{2}\right)$, nitrogen oxides (NOx), mercury and particulate emissions [4] [5]. Any kind of economy-wide mitigation or adaptation effort to climate change must

\footnotetext{
${ }^{1}$ Corresponding author :shankanarayan@gmail.com
} 
have a prominent focus on the electric power sector. Several states in the U.S have adopted stringent targets for "deep reductions" in GHG emissions [6]. States like New Jersey and California have mandated an ambitious GHG emissions reduction target of $80 \%$ by 2050 (compared to 1990 levels for California and 2006 levels for New Jersey) ${ }^{2}$. But there have been very few realistic modeling studies in the literature that have captured the energy and economic changes required to achieve such drastic emissions reduction (except for [6]). Second, a transition to a low-carbon economy requires a rapid decarbonization of the current power generation portfolio. Fripp [7] and Clemmer et al. [8] are examples of research studies motivated by this transition aspect of climate implications on the power sector. Currently, the power industry has various options to implement such a transition. The technology-based options include deployment of more renewables, improvement of heat rates for new and existing plants, a switch to less polluting fuels like natural gas and deployment of advanced carbon capture and sequestration (CCS) technologies. Demand/supply-side operational options include end-use energy efficiency improvements, demand response programs, dynamic pricing mechanism and other smart grid technologies. In addition to reducing $\mathrm{CO}_{2}$ emissions, many of these options also help to reduce other power sector pollutants like $\mathrm{NOx}, \mathrm{SO}_{2}$, mercury and particulate matter. Third, the electric power sector is saddled with assets that have a long economic life. The economic life of a conventional fossil fuel or nuclear power plant is around 40-60 years [4]. Stabilizing global atmospheric carbon levels by midcentury calls for massive deployment of low- to zero-carbon technologies starting today. In order to ensure that the electric power sector is geared up to meet the future challenges of climate change and other market transformations, there is a need to accurately project the multi-decadal trends in systems and markets through models and simulations.

\footnotetext{
${ }^{2}$ For NJ see: http://www.nj.gov/globalwarming/home/gwra report.html \& For CA see: http://www.arb.ca.gov/cc/ab32/ab32.htm
} 
In this paper, we describe a generation/capacity expansion model (GEM/CEM) at a state/regional scale that incorporates the multi-decadal effects of a changing climate and an evolving macro-economy. To accomplish this objective, we use a linear programming based CEM (hereafter referred to as LP- CEM). GEM/CEMs are used to solve the capacity expansion planning problem for the electric power sector. This involves selecting the type of the generating technology to be added to the system; determining the capacity of the generating unit type to be added and the time period at which these capacity additions should take place; ensuring adequate capacity resources to meet the projected future system demand and operating reserve requirements; and projecting the capacity and wholesale price impacts of such expansions on the ratepayers. LP-CEM uses a supply-side cost optimization framework to derive the least-cost expansion plan. An overview of the overall research pathways, the model architecture, scenario definitions and key results from model runs are explained in the following sections.

GEM/CEMs have been extensively studied in the literature (see Kagiannas et al. [9] for a review of GEM/CEMs). These models are predominantly used in the context of a power systems approach to the capacity expansion planning problem. In recent times, these models have been extended to analyze the implications of different policy measures for the electric power sector. Some GEM/CEMs are also used to project the optimal deployment of intermittent renewable resources. Some of the recent peerreviewed research studies using a GEM/CEM modeling framework for extended policy analysis are listed in Table 1.

Nearly all of the reviewed studies use a GEM/CEM framework to model the mitigation and adaptation efforts undertaken by the electric power sector to climate change and variability. A majority of the reviewed studies have relied on large-scale models of the power sector developed at research institutions for quantitative policy analysis (like NREL's ReEDS, EIA's NEMS, IAEA's MESSAGE and PNNL's 
REIF) $)^{3}$. The rest of the reviewed studies have used custom-built models to draw policy inferences about climate change effects on the power sector. Except for Jaglom et al. [10], none of the reviewed studies have attempted to model climate change effects on the demand and supply-side in an integrated manner. Here we attempt to model the climate induced effects on both the demand and supply-sides of the electric power sector and integrate them in a supply-cost optimization framework. In addition, we have also coupled the LP-CEM model to a detailed macroeconomic model of New Jersey. The rationale for this inter-model "coupling loop" is explained in Section 3.2. LP-CEM is used to investigate the overall societal cost of climate change effects for New Jersey ratepayers for the years 2013-2040. To do so, the model also incorporates recent estimates of capital and operating costs of power plant units; anticipated trends in generating technologies; transmission, operating reserves and other technical constraints; and near-term energy policies, regulations and mandates that will have an impact on the future generation portfolio.

This paper's contribution to this broad body of literature on GEM/CEMs is twofold. First, it is one of the few studies in the literature to integrate the climate change effects in both the demand and supply-side using "downscaled" climate projections. We could find only three other peer-reviewed studies that have integrated a detailed climate input into a capacity expansion model $[10,11,12]$. LP-CEM uses detailed hourly temperature projections data to model the changes to system demand. Likewise the constraints to generation and transmission are modeled based on parametric estimates of temperature change effects. These changes are integrated and modeled as constraints in a linear optimization framework. Secondly, none of the other reviewed studies have coupled their input or output to a regional or state-

\footnotetext{
${ }^{3}$ NREL-National Renewable Energy Laboratory (see Short et al. [22] for ReEDS description); EIA-Energy Information Administration (see EIA [49] for NEMS overview); IAEA- International Atomic Energy Agency (see Lucena et al. [11] for model overview). PNNL- Pacific Northwest National Lab (see Kraucunas et al. [50] for REIF overview).
} 
level macroeconomic model. To accomplish this objective, this paper uses R/ECON ${ }^{\top M} 4$, a detailed macroeconomic model for the state of New Jersey. Through this inter-model coupling, the price elasticity of electricity demand and broader electricity price effects on other sectors of the economy are captured in the modeling framework. R/ECON ${ }^{\mathrm{TM}}$ projects changes to retail electricity prices and sectoral composition of electricity demand (i.e. Residential, Commercial and Industrial) over a thirty-year period. LP-CEM uses these inputs to compute the trends in wholesale/retail electricity prices and capacity expansion under a climate change scenario with different growth rates for the economy. To provide a comparative basis for these estimates, the model outcomes are compared to a scenario that does not incorporate climate effects. LP-CEM is configured to model the whole of the Northeast of United States. The rationale for this arrangement is that electric power grid is interconnected by means of transmission networks, and those transmission networks do not match the geographic boundaries of the states. Also, it is often the case that capacity resources in a nearby network/state could serve the demand in one particular state, i.e. the demand in New Jersey can be supplied by generation resources in the region/network. For coupling purposes with an economic model, this paper restricts the discussion of results to New Jersey alone. New Jersey is a highly urbanized state with high income levels and a strong service economy. New Jersey's policy and technology choices for the power sector have broader relevance for other Northeastern states as well.

\section{Methods}

The detailed model architecture, data pathways and assumptions are explained in this section.

\subsection{Temperature projections from NCAR-CESM simulation run}

\footnotetext{
${ }^{4} \mathrm{R} / \mathrm{ECON}^{\mathrm{TM}}$ is a quarterly structural econometric time-series model of New Jersey. It consists of over 250 equations that estimate, among other things, state GDP, personal income, inflation, energy prices, demand, unemployment, local and state tax revenues etc. - http://policy.rutgers.edu/cupr/recon/about.php
} 
The current modeling effort encompasses the electric power system in the U.S. Northeast region. Broadly this includes the network of physical assets used in the generation, transmission, distribution and use of electricity. This system is subject to different climate change and economic growth perturbations. The climate change perturbation is in the form of temperature projections for three local sites in New Jersey. Climate data can be broadly classified under two categories: observational and projected type (see $[13,14,15,16]$ for an overview of recent climate data advances). Observational climate data includes the actual weather variables recorded by weather stations. Projected or simulated climate data are obtained from general circulation/global climate model (GCMs) runs. GCM projections differ based on the nature of initial conditions assumed at the start of simulation, numerical methods used to solve the model equations, spatial resolution of the model run, and assumptions about the interaction effects of different geophysical processes [17]. For the current modeling effort, we rely on a high emissions pathways known as Representative Concentration Pathway 8.5 (RCP 8.5) (see [18, 19]). RCPs are standardized emission pathways used in climate change impact studies. LP-CEM uses temperature projections from National Center for Atmospheric Research (NCAR)'s Community Earth System (CESM) model runs [20]. For this research project, a regional version of CESM was executed with an adaptive grid on the Mid-Atlantic region. CESM outputs are calibrated to historical observations till the end of the year 2004. The simulated runs are used to predict the climate variables from 2005 till 2050. Among the climate variables simulated by CESM model run, we use temperature projections at three local sites in New Jersey. These sites are assumed to be representative of the weather patterns in the state. Figure 1 denotes the average of the temperature trends for New Jersey under a RCP 8.5 emissions pathway. For the years 1980-2050, the average annual temperature for the state increases by $0.058^{\circ} \mathrm{F} / \mathrm{yr}$. The current set of model runs do not consider other climate change effects like precipitation changes, coastal inundations and other disruptive climate tendencies (like changes in frequency/severity of extreme events). 


\subsection{R/ECON ${ }^{\mathrm{TM}}$ model inputs}

The second major perturbation to the system is the different macroeconomic trends for the corresponding simulation period. The R/ECON ${ }^{T M}$ Econometric Forecasting Model is a highly detailed model of the New Jersey economy. The model is specific to New Jersey, and consists of nearly 300 equations covering all major sectors of the state's economy. The equations are based on historical time series data for New Jersey and the nation. The model forecasts a full range of macroeconomic variables including gross domestic product, prices, personal income, population and labor force, and state tax revenue. It also has energy, real estate, and motor vehicles sectors. The model is used for both forecasting and for impact analysis. The R/ECON ${ }^{\mathrm{TM}}$ model has six key sectors: (1) the industrial sector, including employment, gross domestic product of New Jersey (GDP), wage rates, and price deflators for major industries; (2) the personal income sector; (3) the population and labor force sector; (4) the state tax revenue and expenditure sector; (5) an energy sector for the electric and gas utilities and for fuel oil; and (6) an "other" sector which includes equations for real estate and construction and motor vehicles.

$\mathrm{R} / \mathrm{ECON}^{\mathrm{TM}}$ projects the macroeconomic trends for New Jersey under three pathways: R/ECON ${ }^{\mathrm{TM}}$ Mean, High Growth and Low Growth. These R/ECON ${ }^{\mathrm{TM}}$ pathways have different growth rates for macroeconomic variables such as state GDP, unemployment rates, energy demand and personal income. The R/ECON ${ }^{\mathrm{TM}}$ model assumes the following average annual growth rates in real GDP for 20102040: Mean (2.24\%), High Growth (2.28\%) and Low Growth (2.20\%). Combining these pathways with RCP 8.5 climate projections and climate change effects, results in a matrix of six scenarios (a detailed account of the scenarios is presented in the following section). The data pathways in this analysis are represented graphically in Figure 2. The results from the LP-CEM simulation run are fed back to the R/ECON ${ }^{\top M}$ model to complete the inter-model "coupling loop". In this research, this "coupling loop" is executed for one complete iteration. As a result of this "coupling loop", the demand and retail price projections are revised and fed back into the LP-CEM model. For the reference scenario theme, this 
feedback effect from $\mathrm{R} / \mathrm{ECON}^{\mathrm{TM}}$ model results in a cumulative demand increase of $0.34 \%$ for the years 2013-2040 and a decrease in average annual retail price by $0.02 \%$. This "coupling loop" can be continued until a convergence is achieved in key economic-electric power sector parameters.

\subsection{LP-CEM - Overview}

LP-CEM is a long-term capacity expansion model that minimizes the supply-side costs of delivering electricity to the Northeast region from 2010-2050. The supply-side costs include the energy generation costs from dispatching units; operations and maintenance costs of all operating units, investment costs of new units and transmission costs incurred in meeting the system demand. The Northeast region covers the states in New England region, New York, New Jersey, Pennsylvania, Maryland and Delaware. LP-CEM operates on a seasonal time resolution in a given year (i.e. summer, winter, spring and fall). In addition, demand estimates are also distributed into off- and on-peak periods for each of the four seasons (resulting in a total of eight demand periods). The model uses a real discount rate of $6.5 \%$ to reflect the long-term market rate for capital in the power sector. The cost minimization is also subject to a large number of constraints, including: balancing electricity supply and demand at a given time period; installing capacity resources to meet the operating reserves margin; meeting transmission network constraints and transmission losses; and satisfying the availability factor of each technology type. In addition to these technical constraints, there are the policy-type or scenario-specific assumptions like minimum renewable generation requirement, construction limits on power plants, cost multiplier factor for new investments, and resource availability in each state/sub-regions. Electricity demand, generation and operations costs, fuel cost trends, and installed generation and transmission capacities are exogenously specified in the model. The model does not take into account transmission expansion during the simulation period. Also, LP-CEM does not factor in trade with regions outside of the Northeast. Distributed generation, energy efficiency targets, demand response and energy storage are not assumed for the current set of model runs. There are three key decision variables in the model: 
amount of capacity to build (in MW); power generation (in MWh) from available capacity resources and the amount of power to be transmitted (MWh) between sub-regions in the model. The wholesale and capacity prices of electricity are obtained as the dual of the demand and capacity constraints (see [21, 22]). The dual price reflect the competitive wholesale market price of electricity corresponding to the overall system demand and other technical constraints. The detailed model formulation is summarized in the next section. A simplified representation of the model is presented in Figure 3.

\subsection{Detailed mathematical formulation of the LP-CEM model}

The model is solved in GAMS using CPLEX solver with a run-time of around 3-4 minutes for each scenario run $^{5}$. In GAMS, the standard formulation convention is to declare indices as sets; constants as scalars; given data as parameters; decision variables as variables; and objective function and constraints as equations. The key indices are years, time-periods in a given year, generating technology types and model sub-regions. The key decision variables are additional MW capacity installed in a given year, region and technology type; the amount MWh generation from available units in a given year, region, time-period (by season and peak/off-peak) and technology type; and the amount MWh transmitted from one sub-region to another in a given year and time-period ${ }^{6}$. The key input parameters include the modeling horizon (in years); generating technology types; time-periods (i.e. four seasons and peak/offpeak); sub-regions; generating technology types qualified for RPS; capacity factors by technology types and time periods; initial installed capacity by sub-regions; electricity demand by sub-regions and year; peak demand by sub-regions and year; unit emission factors by technology type; derate factor for

\footnotetext{
${ }^{5}$ The GAMS source code for running the LP-CEM is attached as Appendix-I. Also, a template input and output files for an LP-CEM run are attached as Appendix II and III.

${ }^{6}$ GAMS syntax requires declaring the NPV of supply cost (i.e. objective function) as a decision variable.
} 
generating technologies due to climate change effects; fixed and variable operating costs by generating technology and years; planned generation addition and retirement by technology type and year; unit investment costs of new builds by technology type and years; construction limits on new technology by year and type; transmission links and capacities between sub-regions; maximum transmission limits on each link and transmission loss factor by time periods.

The objective function is to minimize the net present value of supply costs over the modeling horizon. The supply-side costs includes investments costs of new units; generation costs (i.e. fuel costs) of dispatching units; operations and maintenance (O\&M) for existing and new units. The constraints can be broadly classified under two categories: technical and policy-related constraints. The major technical constraints include the energy constraints, capacity/supply constraints, reserve margin constraints and transmission limit constraints. The energy constraint ensures that the MWh generated in a given timeperiod equals the energy demand for the corresponding time-period and sub-region (including the energy dispatched through transmission links). The capacity constraint ensures that there is optimal available capacity to supply the MWh generated in a given time-period, subject to capacity factor and other technical constraints. The reserve margin constraint ensures that there is enough installed capacity (both existing and newly built) to meet or exceed the reserves margin requirements in a given time-period. The transmission limits constraints confirms that the amount of $\mathrm{MWh}$ dispatched through a given transmission link is equal to or less than the available limit on that link. The major policy constraints include RPS constraint, emissions limit constraint and construction limits. The RPS constraint confirms that the MWh generation from qualified renewable sources meets or exceeds the sub-regions' current requirements. The emission limit constraint is used to model a cap on total emissions (if in a case of an emissions cap-and-trade program). Finally, the construction limits constraints places limits on construction of new technology type to account for technological feasibility and resource potential (especially for renewable technologies). 


\section{Set Indices}

$\begin{array}{ll}\boldsymbol{y} & \text { years (alias u) } \\ \boldsymbol{t} & \text { periods in each year } \\ \boldsymbol{i} & \text { generation unit type } \\ \boldsymbol{r} \boldsymbol{n} & \text { sub-regions (alias } \mathrm{r} 2 \text { ) } \\ \boldsymbol{n} & \text { sub-set of i containing the list of renewable generating technologies }\end{array}$

\section{Decision Variables}

$s_{\mathrm{y}, \mathrm{r}, \mathrm{i}}$

$x_{y, t, r, i}$

$\boldsymbol{f}_{y, t, r, 1, r 2}$

cost

\section{Parameters}

\begin{tabular}{|c|c|}
\hline$Y$ & Number of years \\
\hline$T$ & Number of the time periods in a year \\
\hline $\boldsymbol{R}$ & Number of the regions \\
\hline I & Number of generation types \\
\hline$N$ & Number of renewable generation types \\
\hline$E$ & Number of emission pollutants $\left(\mathrm{CO}_{2}, \mathrm{SO}_{2}, \mathrm{NO}_{x}\right)$ \\
\hline$c_{y, i}$ & Generation variable cost for generation type $i$ in year $y(\$ / M W h)$ \\
\hline$a_{y, i}$ & Investment cost for generation type $i$ in year $y(\$ / M W)$ \\
\hline init $_{r_{1}, i}$ & Initial capacity of generation type i in region $\mathrm{r} 1$ at the beginning (MW) \\
\hline fnew $_{y, r_{1}, i}$ & Forced new capacity of generation type $\mathrm{i}$ in region $\mathrm{r} 1$ with online year y (MW) \\
\hline fretire $_{y, r_{1}, i}$ & Forced retirement capacity of generation type $\mathrm{i}$ in region $\mathrm{r} 1$ with retirement year $\mathrm{y}(\mathrm{MW})$ \\
\hline$g_{y, i}$ & Fixed operation and maintenance cost for existing generation type i in year y (\$/MW) \\
\hline $\boldsymbol{h}_{\boldsymbol{y}, \boldsymbol{i}}$ & Fixed operation and maintenance cost for new generation type i in year y $(\$ / M W)$ \\
\hline$\varphi_{y, t, r_{1}}$ & Demand in region $\mathrm{r} 1$ in time period $\mathrm{t}$ in year $\mathrm{y}(\mathrm{MWh})$ \\
\hline$d_{y, t, i}$ & Climate change outage rate of generation type $\mathrm{i}$ in time period $\mathrm{t}$ in year $\mathrm{y}$ \\
\hline hours $_{t}$ & Hours in time period $t$ \\
\hline$c \boldsymbol{f}_{y, t, r_{1}, i}$ & Capacity factor for generation type $i$ in region $r_{1}$ in time period $t$ in year $y$ \\
\hline peak $_{y, r_{1}}$ & Peak load (demand) in year $y$ in region $r 1(\mathrm{MW})$ \\
\hline$m_{y, r_{1}}$ & Reserve margin for region $r 1$ in year $y$ \\
\hline $\operatorname{TMIN}_{y, r_{1}}$ & Yearly minimum renewable generation percentage requirement for region $r 1$ in year $y$ \\
\hline$E M_{e, i}$ & Amount of pollutant $e$ emitted from generation type $i$ (Ibs/MWh) \\
\hline
\end{tabular}

MW capacity installed in a given year, region and technology

MWh generation from available units in a given year, region, time-slice and technology MWh power transmitted from one sub-region to another in a given year and time-slice NPV of supply side cost 
$\boldsymbol{R L E} \boldsymbol{M}_{e, y, r_{1}}$ Regional limit for emission gas $e$ in region $r_{1}$ in year $y$ (Ibs)

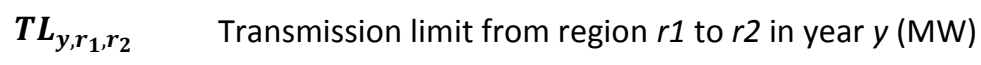

$\boldsymbol{C} \boldsymbol{L}_{\boldsymbol{y}, \boldsymbol{r}_{\mathbf{1}}, \boldsymbol{i}} \quad$ Yearly construction limit of generation type $i$ in region $r 1$ in year $y(\mathrm{MW})$

Scalar

r Discount rate

\section{Objective Function}

$$
\begin{aligned}
\text { minimize COST } & =\sum_{y=1}^{Y}\left(\frac { 1 } { ( 1 + r ) ^ { y } } \left(\left(\sum_{t=1}^{T} \sum_{r 1=1}^{R} \sum_{i=1}^{t} x_{y, t, r 1, i} c_{y, i}\right)+\left(\sum_{r 1=1}^{R} \sum_{i=1}^{I} s_{y, r 1, i} a_{y, i}\right)+\left(\sum_{r 1=1}^{R} \sum_{i=1}^{I}\left(\sum_{u=1}^{y}\left(s_{u, r 1, i}+\text { fnew }_{u, r 1, i}\right)\right) h_{y, i}\right)\right.\right. \\
& \left.\left.+\left(\sum_{r 1=1}^{R} \sum_{i=1}^{I}\left(\text { init }_{r 1, i}-\sum_{u=1}^{y} \text { fretire }_{u, r 1, i}\right) g_{y, i}\right)\right)\right)
\end{aligned}
$$

\section{Equations (constraints)}

$$
\begin{aligned}
& x_{i=1}^{I} x_{y, t, r_{1}, i}^{R} f_{r_{2}=1}^{R, t, r_{1}, r_{2}}+{ }_{r_{2}=1}^{R} f_{y, t, r_{2}, r_{1}}={ }_{y, t, r_{1}} \quad y, t, r_{1} \\
& x_{y, t, r_{1}, i} \leq\left(\text { init }_{r_{1}, i}+\sum_{u=1}^{y}\left(s_{u, r_{1}, i}+\text { fnew }_{u, r_{1}, i} \quad \text { fretire }_{u, r_{1}, i}\right)\right) c f_{y, t, r_{1}, i} d_{y, t, i} \text { hours }_{t} \quad y, t, r_{1}, i \\
& \text { Capacity/Availability } \\
& \text { constraint } \\
& \begin{array}{llll}
\text { init }_{r_{1}, i}^{I}+{ }_{u=1}^{y=1}{ }_{i=1}^{I}\left(s_{u, r_{1}, i}+\text { fnew }_{u, r_{1}, i}\right. & \text { fretire } \left._{u, r_{1}, i}\right) & \text { peak } \\
f_{y, t, r_{1}, r_{1}} m_{y, r_{1}} & & y, r_{1} & \text { Reserve Margin constraint } \\
T_{y, r_{1}, r_{2}} \text { hours }_{t} & y, t, r_{1}, r_{2} & \text { Transmission constraint }
\end{array} \\
& \text { T I }
\end{aligned}
$$

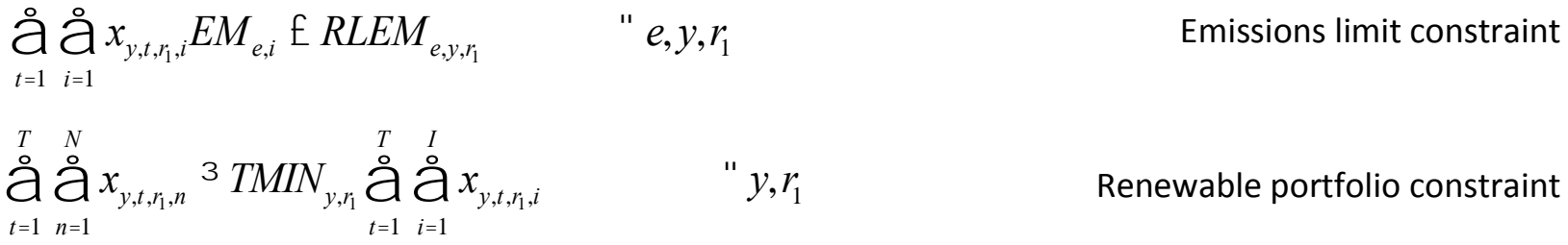



$s_{y, r_{1}, i} \quad C L_{y, r_{1}, i}$
$y, r_{1}, i$
Construction limit constraint
$x_{y, t, r_{1}, i}$
$0, s_{y, r_{1}, i}$
$0, f_{y, t, r_{1}, r_{2}}$
$0 \quad y, t, r_{1}, r_{2}, i$
Positive variables constraint

\subsection{Key input assumptions}

LP-CEM autonomously identifies the timing, the type and the quantity of new generation resources that must be built to satisfy the projected system demand and the technical and policy constraints. The list of possible generation technologies that could be built in the simulation runs include: coal (conventional and advanced), combined cycle (conventional, advanced and advanced with sequestration), combustion turbine (conventional and advanced), nuclear, geothermal, biomass (boiler type), wind turbine (onshore and off-shore), solar photo-voltaic (PV), solar thermal, and hydro-generators (including pumped storage). The cost and performance assumptions for different generating technology types are obtained from EIA's Annual Energy Outlook 2014 [23].This includes assumptions about the type of generating technologies available presently and in the near-term future, fuel costs, overnight investment costs, operations and maintenance (O\&M) costs and capacity factors of generating technologies. The cost and performance data for the current set of model runs are derived primarily from the Reference Case scenario of AEO-2014 [23] report. For some of the scenario runs used in this paper, the growth estimates are also sourced from the High and Low Economic growth scenario used in AEO-2014 (the scenarios are explained in the following section).

The key characteristics of available generation technologies are shown in Table 2. The generating units are subject to technology-specific availability factors (based on [24]). This represents the highest possible capacity factor for each generating technology. Investment costs are assumed to decline over the years based on a minimum learning factor (LR) estimate used in the AEO-2014. Both existing and 
new units also incur fixed and variable operating and maintenance (O\&M) costs. Fixed O\&M costs include expenses incurred at a power plant that do not vary significantly with the amount of $\mathrm{MWh}$ generation (e.g. expenses like salaries of personnel, depreciation costs of assets, facility maintenance and administrative expenses). Variable O\&M costs includes expenses that vary with the amount of power generated at the plant (e.g. cost of cooling water supply, chemicals used in scrubbing equipment, lubricants used in machinery and wastewater disposal) (see [25] for a detailed list of cost factors). In addition to these costs, fuel costs are also incurred by applicable units. The costs estimates for different fuels on a \$/MMBTU basis are based on the AEO-2014 report (i.e. unit cost for coal, natural gas, distillate fuels and wood biomass). The fuel cost escalation rates are based on R/ECON ${ }^{\mathrm{TM}}$ projections for the respective scenario themes. Investments in conventional generating technology types are not subject to any kind of technical/ economic potential cap. The renewable energy investments (in MW) are capped based on the resource potential estimated for states in the Northeast region in Lopez et al. [26]. The technical potential for grid-interactive geothermal and concentrated solar power is estimated to be zero for the Northeast region (also see [27]). The investment costs are also subject to a regional adjustment factor to account for the interstate cost variations of constructing a new power plant.

The model account for three major pollutants from electric generating units: $\mathrm{CO}_{2}, \mathrm{SO}_{2}$ and $\mathrm{NOx}$. Currently, the caps imposed by EPA's Acid Rain Program for $\mathrm{SO}_{2}$ and $\mathrm{NOx}$ are higher than the power sector emissions from the Northeast region ${ }^{7}$. Hence the $\mathrm{NOx}$ and $\mathrm{SO}_{2}$ caps are not binding for the current set of LP-CEM simulation runs. Also, the annual $\mathrm{CO}_{2}$ emissions from the power sector are not subject to any kind of cap in the model. This assumption for $\mathrm{CO}_{2}$ emissions reflects an emissions pathway that is likely to occur in the absence of any future mitigation policy or regulatory constraints on a regional or national scale. The existing MW capacity for the sub-regions in the Northeast for year 2010 is based on EIA's state level database [25]. The existing capacity is the same for all six scenario runs (see

\footnotetext{
${ }^{7}$ See US EPA-Acid Rain Program : http://www.epa.gov/airmarkets/progsregs/arp/index.html
} 
Table 3). This data is also confirmed with the AEO-2014 database to ensure that the generation resources are distributed appropriately within the sub-regions.

The projected demand estimates for all sub-regions, except New Jersey, are based on AEO-2014 estimates (corresponding to the chosen economic growth scenario). The demand projection for New Jersey is based on Load Duration Curves (LDCs) plotted using temperature projections from CESM RCP 8.5 and economic projections (i.e. electricity demand by sectors) from R/ECON ${ }^{\mathrm{TM}}$ model runs. We use a Weather Response Function (WRF) of a utility based in New Jersey to track the changes in hourly system demand for a typical customer class (i.e. residential, commercial or industrial). These WRFs are regression equations linking surface temperature to electricity demand [28]. In addition, these WRFs take into account the type of customer class, type of day (weekday or weekends) and type of hours (peak and off-peak). We then project these changes at a system level for each sector to see the overall trends in demand. Summing up the demand estimates for each sector we get the load profile curves for total demand (see Figure 4). The New Jersey LDCs are plotted for every ten years with demand estimates in the intervening years interpolated to match the trends.

The advantage of this approach, compared to merely assuming a constant growth rate, is that it also captures the changes in the shape of the load profile over the years. Figure 4 shows two key effects. The system peak is becoming sharper over the years and the maximum hourly variations in a given year is also increasing over the years. This shift could be attributable to factors such as economic and population growth, changes in sectoral composition of demand over the years and climate change effects. For New Jersey, the share of industrial and residential sector demand is set to decline in the coming decades. This decline corresponds to the increase in the share of commercial sector to the total demand. Under Reference scenario, the share of commercial demand increases from $51 \%$ in 2010 to $61 \%$ in 2040; the share of residential demand decreases from $38 \%$ in 2010 to $32 \%$ in 2040 and the share of industrial demand declines from $10 \%$ in 2010 to $6 \%$ in 2040 . To illustrate the effects of climate 
change, the LDCs for the year 2040 is plotted using the NCAR-CESM projected weather and a baseline 2010 weather (as a hypothetical example). The difference in system peak demand is estimated to be 870 MW for the two pathways. The sharp increase in system peak demand is likely to result in the addition of peaking and intermediate units in the wider New Jersey region (i.e. mostly combined cycles and combustion turbines) under BAU assumptions. These hypothesized effects will be examined in the results from LP-CEM model runs. The peak demand estimates for other sub-regions in the Northeast are not readily available from the AEO-2014 report. Hence, the peak demand estimates are sourced from an Eastern Interconnection Power Consortium (EIPC) study on the future expansion of the Eastern Interconnection power grid [29]. The baseline projections from [29] are used for the Reference scenario runs. For the High Growth theme, these peak demand projections are escalated to a higher rate (i.e. $10 \%$ more than the Reference scenario escalation rate). Correspondingly for the Low growth theme, the peak demand projections are escalated at a lower rate (i.e. $10 \%$ less than the Reference scenario escalation rate).

On the supply-side, the LP-CEM models the constraints on transmission and generation of power. Transmission networks between states/load zones are simplified to a "transport model" with limits on overall transfer capabilities. LP-CEM does not model transmission network expansion for the current set of model runs (some other GEMs like NREL's REEDS and SWITCH factor in transmission expansion as well; see [7] [22]). The cost of transmission is fixed at $\$ 4$ per MWh based on cost estimates furnished by system operator in the region for the year 2010 and assumed to increase at $1 \%$ every year. The transmission loss factor varies by season and year. The losses are acute in summer and in the later years when climate change effects are more pronounced. Transmission loss factors are based on the estimates found in the literature (see $[30,31,32,33])$. The planning reserve margin for each sub-region ranges from 15-16.5 \% based on available data from the system operators (summarized and presented in [29]). Planned capacity retirements are based on EIA estimates used in AEO-2014 report. Construction 
limits for generating technologies are based on technological feasibility (for new technologies with carbon sequestration) and resource potential (i.e. for renewables like solar, hydro, wind and biomass).

The supply-side constraints are modeled by generation outage factors. This outage factor constrains the potential $\mathrm{MWh}$ of electricity that could be generated from a given generating technology. The generation outage factor is more pronounced in the summer months when the ambient temperature increase and cooling water availability is constrained. This generation outage factor is in addition to the capacity factor for each generating technology. Since the effect of climate change on renewable energy potential is unclear in the literature, the output from renewable energy sources is not subject to any generation outage factor (see [32] and [33] for a review on the current state of the impact literature).

\subsection{Scenarios used in LP-CEM simulation runs}

This paper models a total of six scenarios to analyze the power sector impacts of climate change. The three major scenario themes considered are: Reference case, High growth case and Low growth case. Each scenario theme is compared with and without climate change effects on both the demand and supply-side thereby resulting in a total of six scenarios. The R/ECON ${ }^{\mathrm{TM}}$ projections captures the changes in real GDP, population, personal income growth and employment trends in New Jersey. Total electricity demand/sale for New Jersey is expected to grow by $1.58 \pm 0.03 \%$ a year for the three scenario themes. Likewise the demand projections for other sub-regions are expected to vary depending on the choice of AEO-2014 scenario chosen. The scenarios used in this paper are patterned based on the AEO-2014's Reference case, High Growth and Low Growth case scenarios. On the supply-side the potential generation and transmission is subject to additional outage factors in a scenario incorporating climate change effects. The transmission and distribution (T\&D) loss for the whole of U.S in the year 2010 is estimated to be around 7\%. Since the bulk of these losses are expected to occur in the distribution lines, we have modeled the simple transmission network in our model with a uniform $2 \%$ loss. However, 
under a climate change effect of increased ambient temperature, the thermal limits of transmission lines are easily exceeded [31]. Hence the percentage losses are more pronounced in the summer, followed by spring and fall. These effects are reflected by an increased loss factor ranging from $2-5 \%$ in the later years under a climate change scenario. Likewise on the supply-side, a climate induced-outage factor is introduced to account for the effects of climate change.

Thermal power generation is constrained due to increased ambient air and cooling water temperature. This also reduces the efficiency of power generating units due to decreased temperature differential between the thermal source and sink. Various studies have estimated this decline to be $0.3-1 \%$ loss in MWh generated per ${ }^{\circ} \mathrm{C}$ increase in temperature depending on generating technology type, cooling systems and other climatic assumptions $[30,31,34,35,36][46]$. Based on these estimates, this paper uses an outage factor for $-0.7 \%$ per ${ }^{\circ} \mathrm{F}$ increase for combined cycle units, $-1 \%$ per ${ }^{\circ} \mathrm{F}$ increase for combustion turbine and $-0.5 \%$ per ${ }^{\circ} \mathrm{F}$ increase for nuclear units. The outage factors are extrapolated from average temperature trends projected by the NCAR-CESM model run. The climate change outage is expected to be more severe in summer especially in the years beyond 2030 . This outage factor is also reflective of the possible cooling water shortages or scarcity that is expected to occur in the distant future.

\section{Results and discussion}

In this section, we consider three key output variables from LP-CEM simulation runs. They include: electricity generation (GWh) trends for the Northeast region and New Jersey; type of capacity added $(\mathrm{MW})$ to the region and wholesale/retail price $(\$ / \mathrm{MWh})$ trends. Based on the electricity generation profiles for the Northeast region and New Jersey (Figures 5 and 6 ), three distinct trends are observable. First, the share of electricity generated from advanced combined cycle units is expected to increase substantially in the coming decades. This is likely to replace the share of electricity generated from 
conventional natural gas based units. Overall the share of power generated from conventional natural gas based units is expected to decline from $40 \%$ in 2010 to about $26-27 \%$ in 2040 under different simulation runs. Secondly, the share of power generated from nuclear is expected to increase in the later period of the model simulation (i.e. beyond 2025). The share of nuclear generation is expected to increase from $26 \%$ in 2010 to about $35-39 \%$ by 2040 under the various scenario themes for the Northeast region. This is because new nuclear capacity addition in the model is subject to a mandatory fifteen year waiting period to account for regulatory approval and average construction time. Also, the model takes into account only the planned retirements as available in the AEO-2014 report. Many of the nuclear plants built in the 1960s-1980s are licensed to run for a period of sixty years. There is a possibility that some of the nuclear plants in the Northeast could be decommissioned in the coming decades due to licensing regulations and non-viable power generation costs. Hence, the projected share of the nuclear generation is likely to be overestimated in the model runs. Thirdly, the share of renewables is also expected to grow in the coming decades. Overall, the share of generation from renewables, including hydro, is expected to increase from $12-13 \%$ in 2010 to $19-20 \%$ in 2040.

The existing Renewable Portfolio Standards (RPS) requirements are modeled as a percentage of total generation in a year (around 20-25\% for each sub-region by the year 2025 and remaining constant for the rest of the simulation period). Also, the share of hydro-generation (including pumped storage) in the Northeast is expected to increase modestly in the later years. This is partly due to the fact the hydrounits are factored in as a renewable source for modeling purposes. Even in the absence of any major emissions policy assumptions (i.e. in the current set of model runs), the share of coal generation shows a moderate decline in the coming decades. This partly reflects the non-viable cost economics of generation from coal-based units (see [37]). Power generated from on-shore wind, off-shore wind and biomass is expected to contribute significantly to meet the RPS requirements in the future. Generation from other sources like grid-interactive solar PV and biomass are too small to be discerned clearly in the 
charts. These three key trends are also visible in the case of New Jersey's generation profile (see Figure 5). For New Jersey, the share of in-state generation is poised to decline substantially in the coming decades. By 2040, nearly half of New Jersey's total demand is expected to be met by out-of-state generation resources.

Figure 7 plots the generation capacity mix for the Northeast region under different scenarios. This takes into account planned retirements and capacity additions (both planned and unplanned).The total installed capacity in the Northeast is likely to increase from 152, $000 \mathrm{MW}$ in 2010 to about 172,000 MW - 195,000 MW in 2040 under different scenario assumptions. Generally scenarios with climate change and variability effects have a higher capacity additions to account for generation and transmission constraints. Figure 8 plots the capacity additions by technology type for the whole of Northeast region and by individual sub-regions. For scenarios without climate change effects, the capacity addition is 36,700 MW for Low Growth theme; 38,400 MW for Reference theme and 46,000 MW for High Growth theme. For scenarios with climate change and variability effects, the capacity addition is $36,900 \mathrm{MW}$ for Low Growth theme; 43,100 MW for Reference scenario theme and 56,200 MW for High Growth theme. The bulk of capacity addition is expected to occur in advanced combined cycle units; nuclear and onshore wind (see pie-chart in Figure 8). The installed capacity share of natural gas based technologies is not expected to vary much from 2010 to 2040. The share of renewables is expected to increase from $11 \%$ in 2010 to $17-18 \%$ in 2040 under different scenario themes. Also, the current set of model runs fails to account for unplanned retirements in existing combined cycles and other conventional units. Hence the total installed capacity estimate is likely to be over-estimated in the current simulation runs. Had long-term retirements been factored in the model runs, the quantity of new capacity addition would likely be higher. Retirement decisions of power plants are strictly based on cost economics of power production and regulatory environment of electricity wholesale markets. The Northeast region is characterized by competitive wholesale markets wherein the dispatch of power from individual power 
plants are based on price bids and market clearing price. Under these circumstances, it is difficult to ascertain the long-term plans of individual generation units based on average costs of generation alone. Hence, the model assumes only the planned capacity retirements by load zones/sub-regions which are usually accurate for the near term period.

Finally, we can also project the trends in wholesale and retail prices of electricity under different scenarios from the LP-CEM model runs. The dual variable of the energy and capacity constraint of the model yields the energy and capacity component of the wholesale electricity prices (see Rau, 2003) for theory and formulation behind dual variables). Figure 9 highlights the trends in average wholesale prices over the simulation period. Interestingly, the compound average growth rate (CAGR) for wholesale price projections under all scenario themes more or less corresponds to the fuel cost escalation rate for natural gas (at $2.1 \%$ a year). This is because natural gas units are expected to set the marginal wholesale price at most time periods in the future (in a competitive market framework). Hence the future wholesale electricity prices are expected to be strongly correlated with natural gas prices. Figure 11 projects the retail price trends for the same period. Naturally, the difference in prices is higher under a High Growth scenario theme. Similarly, differences are also higher in the later years due to higher system demand levels and a more pronounced climate change constraint on the supply-side. This results in a high wholesale price deviations for scenarios with and without climate change effects. A High Growth scenario incorporating climate effects has the highest deviation from a reference scenario projection. For the years $2013-40$, the average annual load-weighted wholesale prices are: $\$ 51.40$ $\$ / M W h$ for a low growth scenario with climate effects; $\$ 52.12 \$ / M W h$ for Reference scenario with climate effects and \$ 53.11 \$/MWh for High Growth scenario with climate effects (all prices are in 2012 \$). The corresponding average price for Reference scenario without climate change is around $\$ 50.46$ $\$ / \mathrm{MWh}$. 
Figure 10 plots the corresponding wholesale ratepayer impact for New Jersey customers. The wholesale ratepayers' impact is computed as the sum of the payment made to the energy component and the capacity component of the wholesale electricity prices. All three climate change scenarios have a higher wholesale ratepayer impact on customers in New Jersey. The fluctuations in wholesale price impact are ironed out in the final retail ratepayer impact for New Jersey customers. This is because the wholesale component of the price is only $40-50 \%$ of the final retail price for New Jersey customers [38]. The High growth scenario with climate change effects has consistently high ratepayer impact throughout the simulation period. A low growth scenario has correspondingly the lowest impact for the end consumers. The difference in the wholesale and retail ratepayer impacts after the R/ECON-LPCEM coupling run is plotted in Figure 12. For the years 2013-40, the cumulative difference in wholesale ratepayers' impact due to climate effects is estimated to range from $\$ 884$ million to $\$ 3,868$ million (all terms in NPV 2012 \$). Cumulatively, the difference in retail ratepayers' costs is expected to range from $\$ 1.91$ to $\$ 4.29$ billion under different scenario themes (all terms in NPV 2012 \$). Figure 13 plots the difference in wholesale and retail prices due to climate effects. For the years 2013-40, the average annual increase in final retail price is expected to range from 0.07 to 0.11 cents/kWh (2012 \$). This increase is with reference to $\mathrm{R} / \mathrm{ECON}^{\mathrm{TM}}$ baseline projection and also factors in the elasticity of demand to projected price increase (i.e. after R/ECON-LPCEM coupling).

\section{Conclusion and policy implications}

This paper demonstrates the feasibility of incorporating climate change effects and macroeconomic trends in a GEM/CEM framework. The economic- electricity model "coupling" used in this paper has the additional advantage of analyzing the broader impacts on the macro-economy. This "coupling loop" could be continued until a convergence is achieved in key economic-energy sector parameters. For New Jersey's case, this is accomplished by coupling the LP-CEM model to R/ECON ${ }^{\mathrm{TM}}$ macroeconomic model. Such integrated models can be of use to state/regional policymakers related to the electric power sector 
to plan for future mitigation and adaptation polices, and to assess the impacts of various policy interventions on energy investments and macroeconomic outcomes. The R/ECON-LPCEM modeling framework can be used to implement a long-term mitigation policy roadmap for the power sector in New Jersey and wider Northeast region. The LP-CEM model also provides a framework to project the societal costs of future mitigation policies targeting the electric power sector. The business-as-usual (BAU) scenarios runs in this paper demonstrates the effects of temperature increase on electricity demand and resulting impacts on electricity supply, investments and broader macroeconomic effects. The BAU scenarios highlight the importance of capturing the effects of climate variables like temperature. In the absence of any major mitigation and adaptation policies, the climate effects result in an increase in supply costs, electricity prices and ratepayer's impacts. Ignoring the future climate effects could inflate the relative costs of any potential mitigation policies and also lead to possible underinvestment in such policies (see [10]).

Based on temperature projections from NCAR CESM, the annual monthly average surface temperature in New Jersey is expected to increase on average by around $2.3^{\circ} \mathrm{F}$ by 2050 (as compared to 2010). This temperature increase affects electricity demand for the state. It also increases the peak system demand for the state (as shown in Figure 4). Higher electricity demand calls for increased electricity supply and capacity investments. As shown in the LP-CEM simulation results section, scenarios with climate effects and high economic growth rates have higher capacity additions. This calls for state regulators (like public utilities commission (PUCs)), electric power utilities, independent power producers (IPPs), and independent system operators/regional transmission organizations (ISOs/RTOs) to incorporate climate effects and macroeconomic trends in long-term investment planning for the power sector. Ignoring the long-term temperature effects may result in an underestimation of the demand and supply-side vulnerabilities of electric power sector to climate change. 
The results from the LP-CEM modeling framework should be viewed as an attempt to better understand and project the likely real-world trends. The estimates derived from this research highlights the likely direction and order of magnitude of the impacts of climate change and macro-economic trends on electric power sector. The following results for New Jersey/Northeast region could serve as pointers for policymakers to plan for future adaptation, mitigation and power sector investment policies. It should be noted that no modeling framework can accurately capture the evolution of real-world systems under uncertainty. The following modeling results should be interpreted with these limitations under considerations.

- Scenarios with climate variability, climate change effects and high economic growth rates have higher capacity additions (in MW), supply costs, prices and ratepayers' costs. This is based on the simulation results from the various BAU runs for the Northeast region under different economic growth rate and temperature pathway assumptions.

- From the LDC modeling effort and LP-CEM simulations, the bulk of the capacity addition is expected to be advanced combined cycle units for the Northeast region in the next forty years. These units can supply to both intermediate and peak system demand. Nuclear and on-shore wind additions are also likely to be considerable in the coming decades for the Northeast region (based on cost-economics considerations alone).

- The future wholesale electricity price escalation rates are expected to be strongly correlated with natural gas fuel cost escalation rates. This is due to the fact that natural gas based units are expected to set the system marginal price for most time periods in the future (under a competitive market framework).

- For the years 2013-2040, the cumulative increase in wholesale ratepayers' impact due to climate change and variability effects is estimated to range from $\$ 0.8$ billion to $\$ 3.8$ billion (all 
terms in NPV \$) under different scenario themes. This represents the increase in wholesale cost of electricity for ratepayers in New Jersey due to long-term temperature effects alone.

- For the years 2013-2040, the cumulative increase in retail ratepayers' costs is expected to range from $\$ 1.9$ to $\$ 4.3$ billion under different scenario themes (all terms in NPV \$). This increased energy cost is likely to have ripple effects on the wider macro-economy of New Jersey. This ratepayer cost increase is computed with reference to a baseline $\mathrm{R} / \mathrm{ECON}^{\mathrm{TM}}$ projection.

- For the years 2013-2040, the average annual increase in final retail price for New Jersey is expected to be around $0.08-0.11$ cents/kWh (2012) assuming climate change and variability effects on the wholesale price component alone. The final effect on the retail prices are most likely to be higher if the effects of climate change on distribution, ancillary services, market regulation and taxes, are also factored in.

Some of the limitations and possible improvements to the modeling approach presented here should be noted. First, the different climate and macroeconomic assumptions are dependent on underlying parameters like demand levels, relative costs of generation technologies, technical feasibility and fuel costs. It would be useful to expand on the range of scenarios in future studies (using multiple climate model projections, temperature increase parameters, macroeconomic and technological cost assumptions). Second, we model the impact pathway of surface temperature on the power sector. In future, it is possible to expand the R/ECON-LPCEM platform to model the impact pathways of other physical variables like precipitation, wind speed, cloud cover, and solar radiation measurement. Third, the current version of the LP-CEM optimization model operates on a deterministic framework which assumes perfect foresight over a future planning horizon. Climate impacts, on the other hand, are usually characterized by high degree of uncertainty. In the future, we are hoping to address some of the climate uncertainty by relying on an ensemble of "downscaled" GCM projections; incorporating the parametric distribution of climate impact variables (like climate induced outage factors and transmission 
losses); and running multiple simulation runs of LP-CEM model to arrive at the expected cost estimates. Finally, the modeling approach used in this study did not consider the impact of extreme weather events. The R/ECON-LPCEM modeling platform can be enhanced through a better understanding of the underlying geophysical processes behind extreme events and the associated impact pathways on the various socio-economic systems. In the near term, the model framework can be improved through a stochastic specification of damage cost function or through a robust optimization approach with suitable probability weights attached to climate-economy scenarios.

\section{Acknowledgement}

This research was supported from a National Science Foundation (NSF) Grant under Award Number: OCE 1049088. We are grateful to David Coit, Xiaojun Shan and Rasika Athwale for comments and suggestions. We also thank our colleagues at the National Center for Atmospheric Research (NCAR) for the climate projections and Enrique Curchitser for his guidance in making the linkage between climate model outputs and the variables required for the electricity model. 


\section{References}

[1] J. Hansen, P. Kharecha, M. Sato, V. Masson-Delmotte, F. Ackerman and e. al, "Assessing "Dangerous Climate Change": Required Reductions of Carbon Emissions to Protect Young People, Future Generations and Nature," PLoS One, vol. 8, no. 12, 2013.

[2] IPCC, 2013: Summary for Policymakers., in Climate Change 2013: The Physical Science Basis. Contribution of the Working Group I to the Fifth Assessement Report of the Intergovernmental Panel on Climate Changw, Cambridge, UK \& New York, US, University of Cambridge Press, 2013.

[3] J. M. Mellilo, T. Richmond, G. Yohe and (Eds.), "Climate Change Impacts in the United States: The Third National Climate Assessment Report," US Global Change Research Program, Washington DC, 2014.

[4] G. Morgan, J. Apt and L. Lave, "The U.S Electric Power Sector and Climate Change Mitigation," Pew Center-Carnegie Mellon University, 2005.

[5] EPA, "Global Greenhouse Gas Emissions Data- Electricity Sector Emissions," January 2014. [Online]. Available: http://www.epa.gov/climatechange/ghgemissions/global.html.

[6] J. H. Williams, A. DeBenedictis, R. Ghanadan, A. Mahone, J. Moore, W. R. Morrow, S. Price and M. S. Torn, "The technology path to deep greenhouse gas emissions cuts by 2050: The pivotal role of electricity," Science, vol. 335, pp. 53-59, 2012.

[7] M. Fripp, "Switch: A Planning Tool for Power Systems with large shares of Intermittent Renewable Energy," Environmental Science \& Technology, pp. 6371-6378, 2012.

[8] S. Clemmer, J. Rogers, S. Sattler, J. Macknick and T. Mai, "Modeling low-carbon US Electricity futures to explore impacts on national and regional water use," Environmental Research Letters, vol. 8, 2013.

[9] A. Kagiannas, D. Askounis and J. Psarras, "Power Generation Planning: A survey from monopoly to competition," International Journal of Electrical Power and Energy Systems, vol. 26, pp. 413-421, 2004.

[10] W. Jaglom, J. McFarland, M. Colley, C. Mack and et-al., "Assessment of projected temperature impacts from climate change on the U.S power sector using the Integrated Planning Model," Energy Policy, pp. 524-539, 2014.

[11] A. F. P. Lucena, R. Scaeffer and A. S. Szklo, "Least-cost adaptation options for global climate change impacts on the Brazilian electric power system," Global Environmental Change, pp. 342-350, 2010.

[12] V. Taseka, N. Markovska and J. Callaway, "Evaluation of climate change impacts on energy demand," Energy, pp. 88-95, 2012.

[13] G. Meehl, C. Covey, T. Delworth, M. Latif, B. McAvaney and e. al., "The WCRP CMIP3 Mutimodel 
Dataset- A New Era in Climate Change Research," Bulletin of American Meteorological Society, pp. 1383-1395, 2007.

[14] J. Overpeck, G. Meehl, S. Bony and D. Easterling, "Climate Data Challenges in the 21st Century," Science, pp. 700-702, February 2011.

[15] K. Taylor, R. Stouffer and G. Meehl, "An Overview of CMIP5 and the Experiment Design," Bulletin of American Meteorological Society, pp. 485-495, 2012.

[16] S. Chandramowli and F. Felder, "Climate change and power systems planning- Opportunities and Challenges," Electricity Journal, pp. 50-60, 2014.

[17] B. Stevens and S. Bony, "What are climate models missing?," Science, pp. 1053-1054, 2013.

[18] R. H. Moss, J. A. Edmonds, K. A. Hibbard, M. R. Manning, S. K. Rose, D. P. v. Vuuren, T. R. Carter, S. Emori, M. Kainuma, T. Kram, G. A. Meehl, J. F. B. Mitchell, N. Nakicenovic and K. R. , "The next generation of scenarios for climate change research and assessment," Nature, vol. 463, pp. 747754, 2010.

[19] D. van Vuuren, J. Edmonds, M. Kainuma, K. Riahi, A. Thomson, K. Hibbard and et al., "The Representative Concentration Pathways: An overview," Climatic Change, pp. 1095-31, 2011.

[20] NCAR, "Community Earth System Models," May 2014. [Online]. Available: http://www2.cesm.ucar.edu/.

[21] N. Rau, Optimization Principles- Practical Applications to the Operation and Markets of the Electric Power Industry, IEEE Press and Wiley- Interscience, 2003.

[22] W. Short, P. Sullivan, T. Mai, M. Mowers, C. Uriate, N. Blair, D. Heimiller and A. Martinez, "Regional Energy Deployment System(ReEDS)," National Renewable Energy Laboratory(NREL), Golden, Colarado, 2011.

[23] EIA-AEO, "Annual Energy Outlook Report 2014," Energy Information Administration (EIA), Washington DC, 2014.

[24] R. Tidball, J. Bluestein, N. Rodriguez and S. Knoke, "Cost and Performance assumptions for modeling electricity generation technologies," National Renewable Energy Laboratory (NREL)-ICF International, Boulder, CO, 2010.

[25] EIA, "Form EIA-923 Detailed Data," Oct 2013. [Online]. Available: http://www.eia.gov/electricity/data/eia923/.

[26] A. Lopez, B. Roberts, D. Heimiller, N. Blair and G. Porro, "U.S Renewable Energy Technical Potentials: A GIS-based Analysis," National Renewable Energy Laboratory(NREL), Boulder,CO, 2012.

[27] J.W.Tester, B. Anderson, A. Batchelor, D. Blackwell, R. DiPippo, E. Drake, J. Garnish and et-al., "The future of geothermal energy," MIT Press, Cambridge,MA, 2006. 
[28] JCPL, "JCPL Load Profile Application," January 2013. [Online]. Available: https://www.firstenergycorp.com/content/dam/supplierservices/files/loadprofile/Load\%20Profile \%20Application\%20JC\%20CLEAN_V2.pdf.

[29] Eastern Interconnect Planning Collaborative (EIPC), "Modeling Results: Futures and Sensitivities," December 2013. [Online]. Available: http://www.eipconline.com/Modeling_Results.html.

[30] M. van Vliet, J. Yearsley, F. Ludwig, S. Vogele, D. Lettenmaier and P. Kabat, "Vulnerbaility of US and European electricity supply to climate change," Nature Climate Change, pp. 676-680, 2012.

[31] J. A. Sathye, L. L. Dale, P. H. Larsen, G. A. Fitts, K. Koy, S. M. Lewis and A. F. de Lucena, "Estimating impacts of warming temperature on California's electricity system," Global Environment Change, pp. 499-511, 2013.

[32] Department of Energy (DOE), "U.S Energy Sector Vulnerabilities to Climate Change and Extreme Weather," U.S Department of Energy, Washington DC, 2013.

[33] S. Chandramowli and F. Felder, "Impact of climate change on electricity systems and markets- A Reveiw of Models and Forecasts," Sustainable Energy Technolgies and Assessments, pp. 62-74, 2014.

[34] A. Durmayaz and S. Sogut, "Influence of cooling water temperature on the efficiency of a pressuired water reactor nuclear-power plant," Journal of Energy Research, pp. 799-810, 2006.

[35] J. Maulbetsch and M. DiFilippo, "Cost and Value of Water Use at Combined Cycle Plants," California Energy Commission (CEC), 2006.

[36] P. Linares, F. J. Santos, M. Ventosa and L. Lapiedra, "Incorporating Oligopoly, CO2 emissions trading and green certificates into a power generation expansion model," Automatica, vol. 44, pp. 16081620, 2008.

[37] D. Schlissel, "Beyond the Hype: The Future of Coal in the U.S," in AAAS- Annual Meeting 2013, Boston, MA, 2013.

[38] Center for Energy, Economic and Environmental Policy (CEEEP), "Analysis for the 2011 Draft New Jersey Energy Master Plan Update," Rutgers University- Edward Bloustein School of Planning and Public Policy, New Brunswick, NJ, 2011.

[39] Q. Chen, C. Kang, Q. Xia and J. Zhong, "Power Generation Expansion Planning Model Towards LowCarbon Economy and its application in China," IEEE Transactions on Power Systems, vol. 25, no. 2, pp. 1117-1125, 2010.

[40] M. Webster, P. Donoho and B. Palmintier, "Water-CO2 trade-offs in electricity generation planning," Nature Climate Change, pp. 1029-1032, 2013.

[41] J. Logan, A. Lopez, T. Mai, C. Davidson, M. Bazilian and D. Arent, "Natural Gas scenarios in the U.S Power Sector," Energy Economics, vol. 40, pp. 183-195, 2013. 
[42] T. Mai, D. Mulcahy, M. Hand and S. Baldwin, "Envisioning a renewable electricity future for the United States," Energy, vol. 65, pp. 374-386, 2014.

[43] Z. Hu and W. T. Jewell, "Optimal Generation Expansion Planning with Integration of variable renewables and bulk energy storage systems," in 1st IEEE Conference on Technologies for Sustainability(Sus Tech), Portland, Oregon, 2013.

[44] X. Yu, "Impacts Assessment of PHEV Charge Profiles on Generation Expansion using National Energy Modeling System," in IEEE Power and Energy Society General Meeting, Pittsburgh, PA, 2008.

[45] H. Cai, M. Wang, A. Elgowainy and J. Han, "Updated Greenhouse Gases and Criteria Pollutant Emission Factors of the U.S Electric Generating Units in 2010," Argonne National Laboratory, Chicago, US, 2013.

[46] K. Linnerud, T. Mideksa and G. Eskeland, "The impact of climate change on nuclear power supply," The Energy Journal, pp. 149-168, 2011.

[47] L. Bird, C. Chapman, J. Loan, J. Sumner and W. Short, "Evaluating renewable portfolio standards and carbon cap scenarios in the U.S electric sector," Energy Policy, vol. 39, pp. 2537-2585, 2011.

[48] EIA (b), "Updated Capital Cost Estimates for Utility Scale Electricity Generating Plants," US Energy Information Administration (EIA), Washington DC, 2013.

[49] EIA (b), "Integrating Module of the National Energy Modeling System: Model Documentation 2013," US Energy Information Administration (EIA), Washington DC, 2013.

[50] I. Kraucunas, L. Clarke, J. Dirks, J. Hathaway and et-al., "Investigating the nexus of climate, energy, water and land at decision-relevant scales: the Platform for Regional Integrated Modeling and Analysis (PRIMA)," Climatic Change, 2014. 
Figures

Figure 1: Localized monthly-average temperature trends for New Jersey (from NCAR CESM)

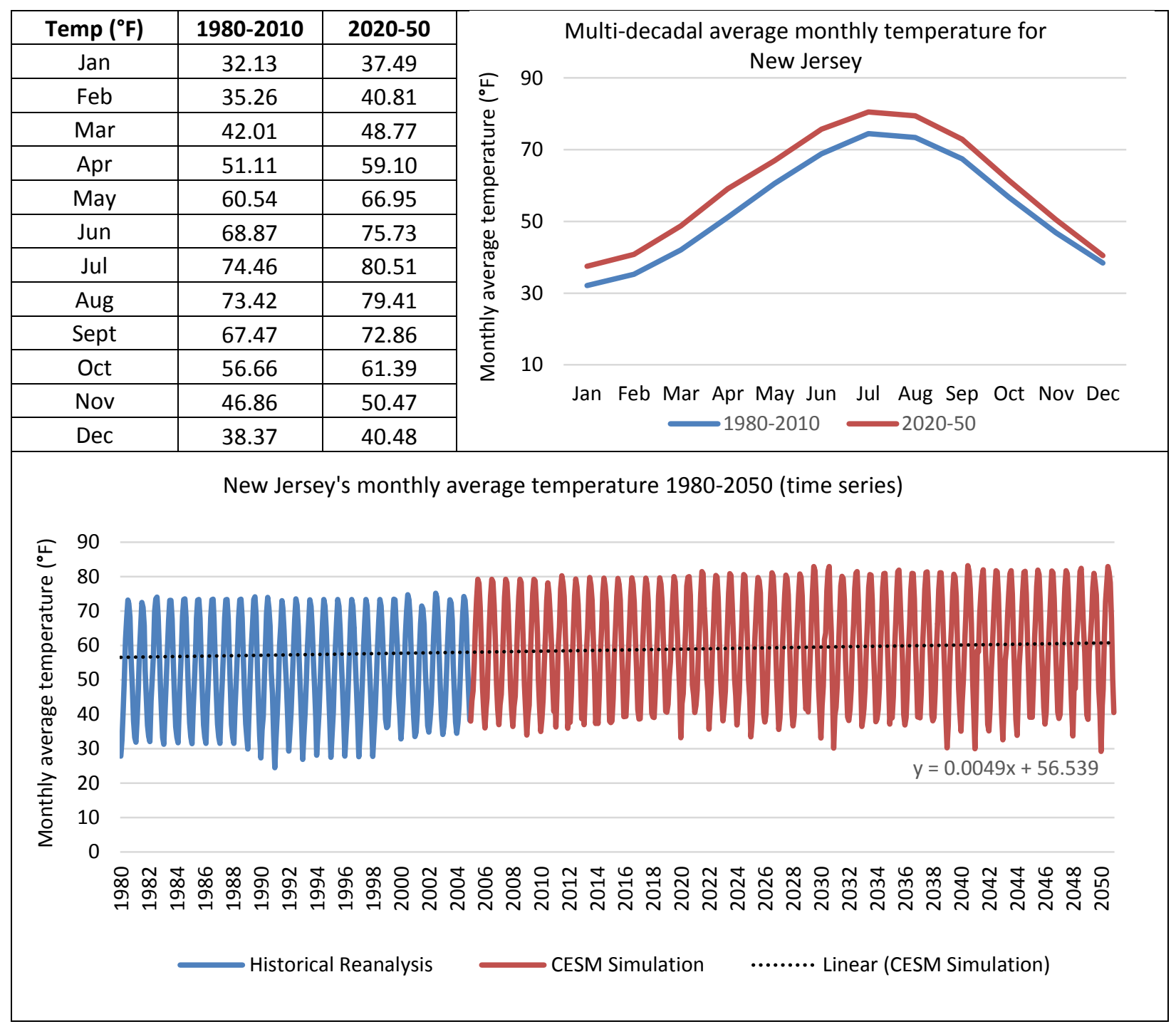


Figure 2: Analytical framework for incorporating climate change effects and macroeconomic trends in LP-CEM

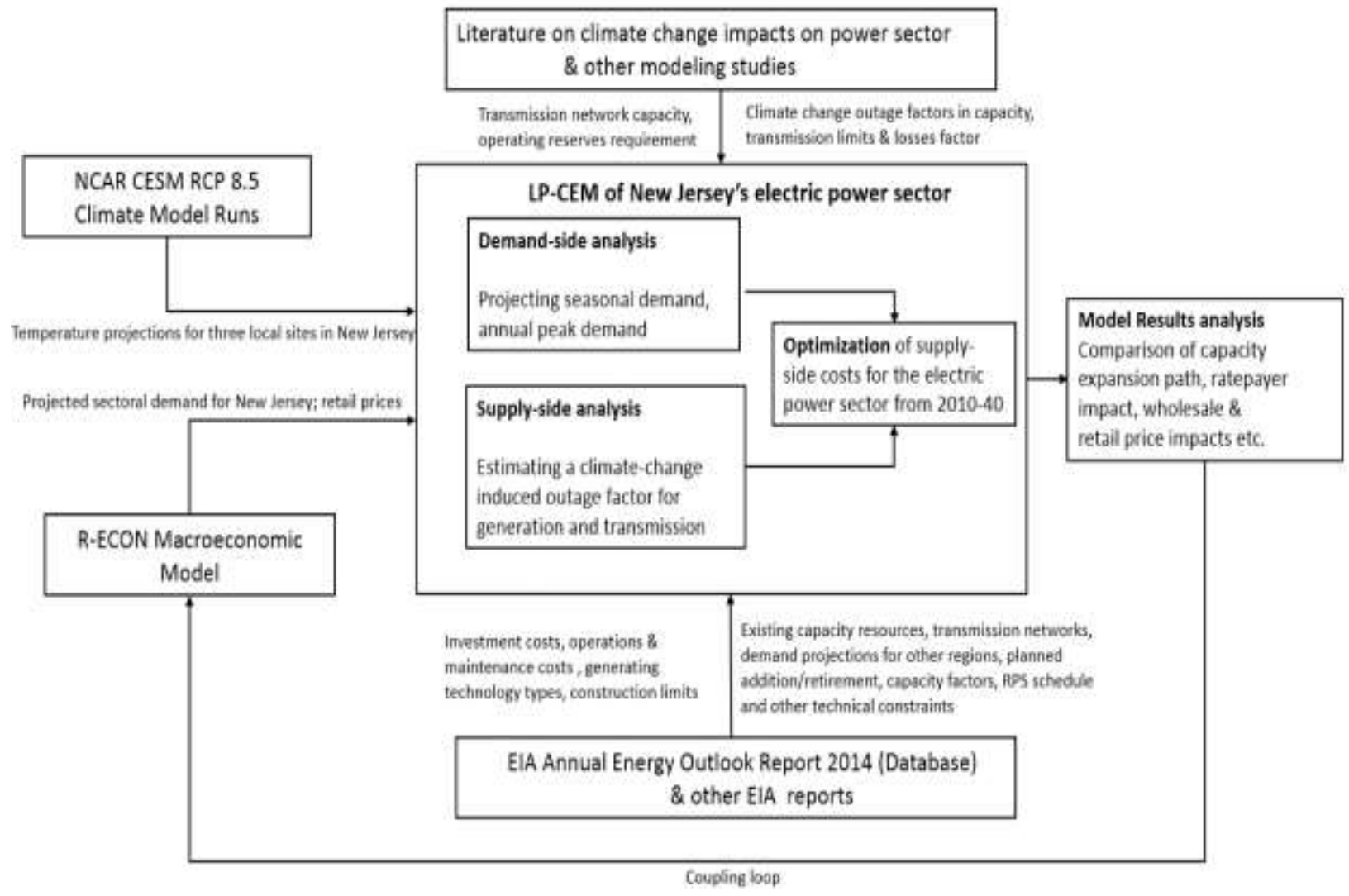




\section{Figure 3: Simplified representation of the LP-CEM architecture}

minimize Net present value of the total supply-side costs (i.e. Investment costs+ O\&M costs + Fuel costs)

subject to the following set of constraints

- Total system demand + Operating reserve + Transmission losses = Total MWh Generation

- MWh generated in a time period $=($ Initial Capacity - Retirement + New Investments $) \times$ Availability factor $\times$ Climate Change Outage factor $x$ Hours in a time period

- Net available capacity $\geq$ Peak demand+Reserve margin

- Inter sub-region transmission(MWh) $\leq$ Transmission capacity(MWh) for respective links

- MWh generation from renewable sources $\geq$ RPS limit for a given sub-region and year

- New renewable MW addition $\leq$ Renewable energy potential(MW) for each sub-region

- Capacity addition of nuclear and new generating technology types is permissible beyond a predefined waiting period (to account for technical feasibility) 
Figure 4: Projected changes in Load Duration Curves (LDCs) for New Jersey

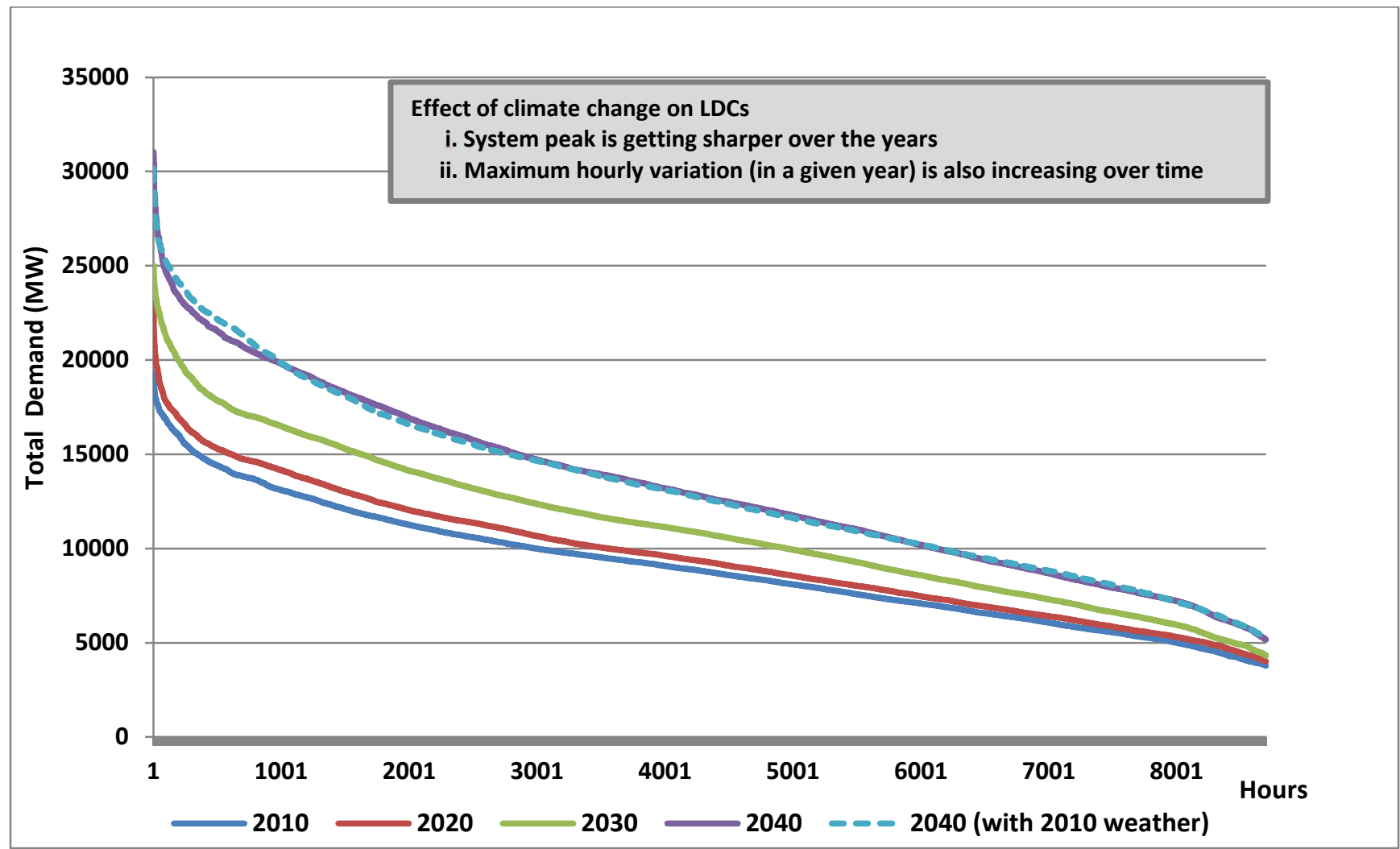

Note: LDCs are used to study the trends in system demand over time. In the X-axis are hours in a typical year (not chronologically arranged). The $\mathrm{Y}$-axis plots the system demand (MW) arranged in a descending order of magnitude. 
Figure 5: Electricity generation and total demand in the Northeast region under different scenarios

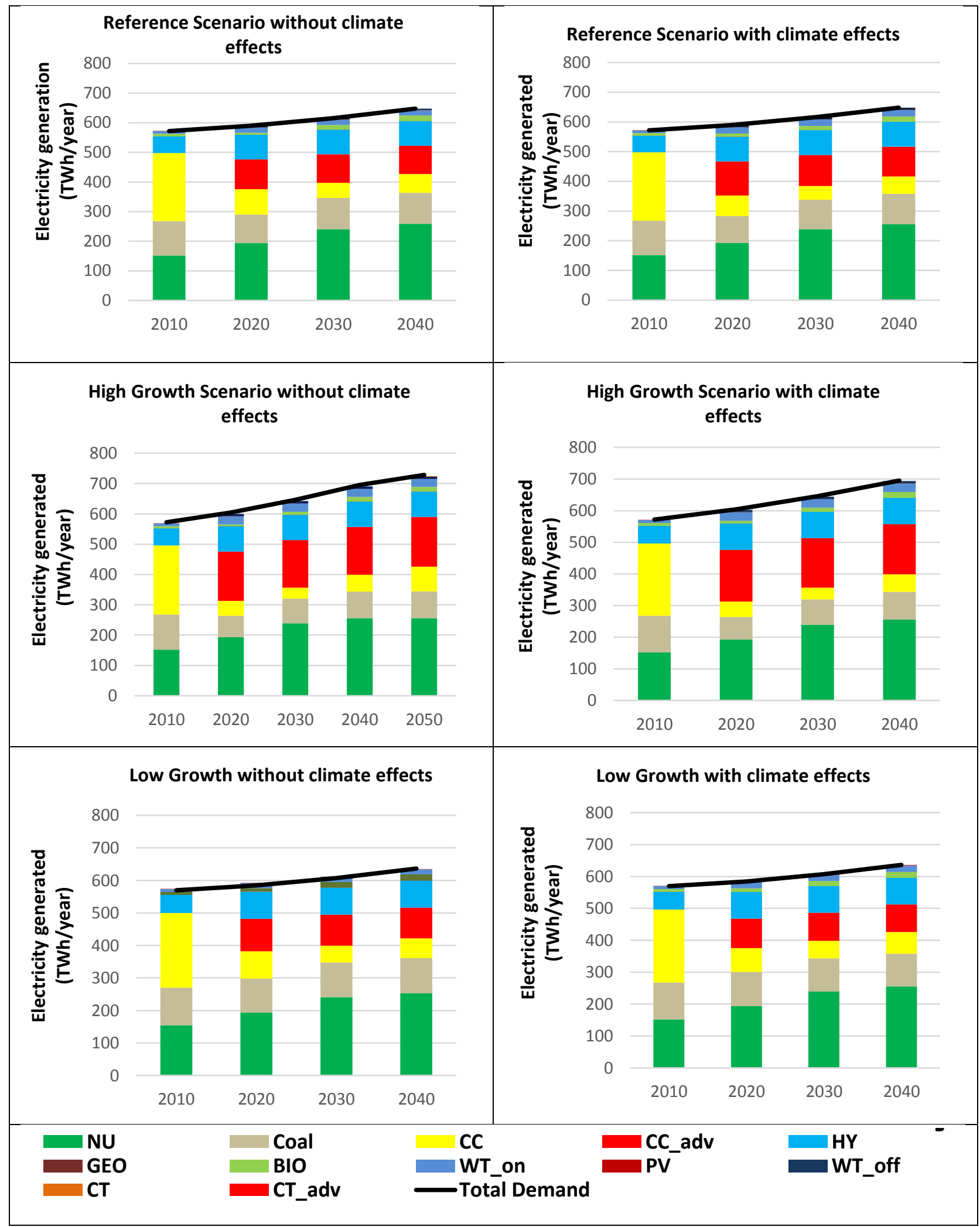

Note: The Northeast region includes the states in New England, New York, New Jersey, Pennsylvania, Maryland and Delaware. 
Figure 6: In-state electricity generation for New Jersey under different scenarios

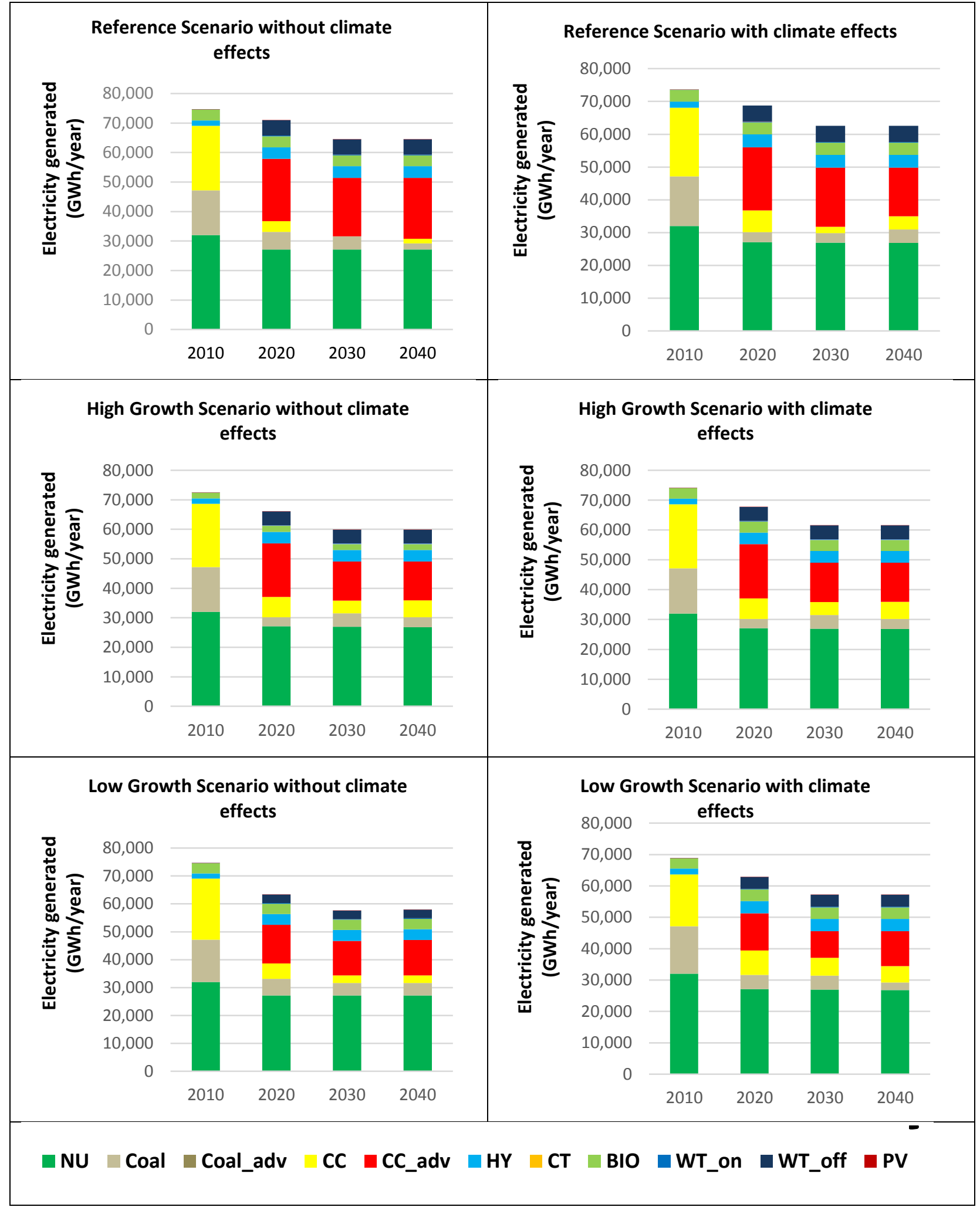

Note: The in-state generation is not expected to correspond to the system demand in the state for all years. 
Figure 7: Total installed generation capacity for the Northeast region under different scenarios

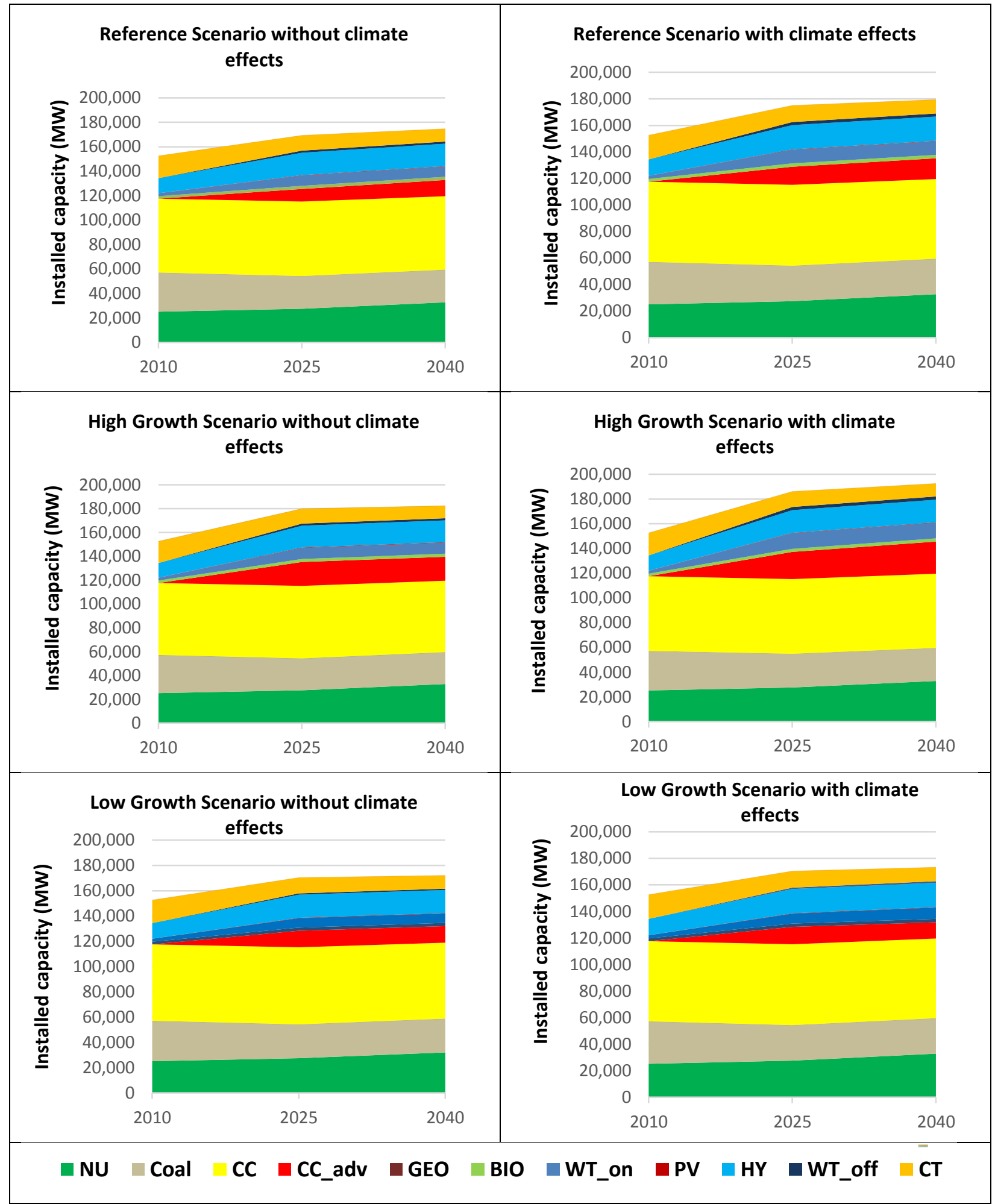

Note: Total capacity installation is represented as a gradual increase from 2010-40 for illustration purposes only. The capacity increase occurs in sporadic batches at different intervening years in this period depending on demand projections and other scenario assumptions. Total capacity installation takes into account the planned retirement and additions of generation capacity. Un-planned retirements are ignored in the simulation runs. 
Figure 8: Capacity addition by technology type and sub-regions 2010-40 (for select scenarios alone)

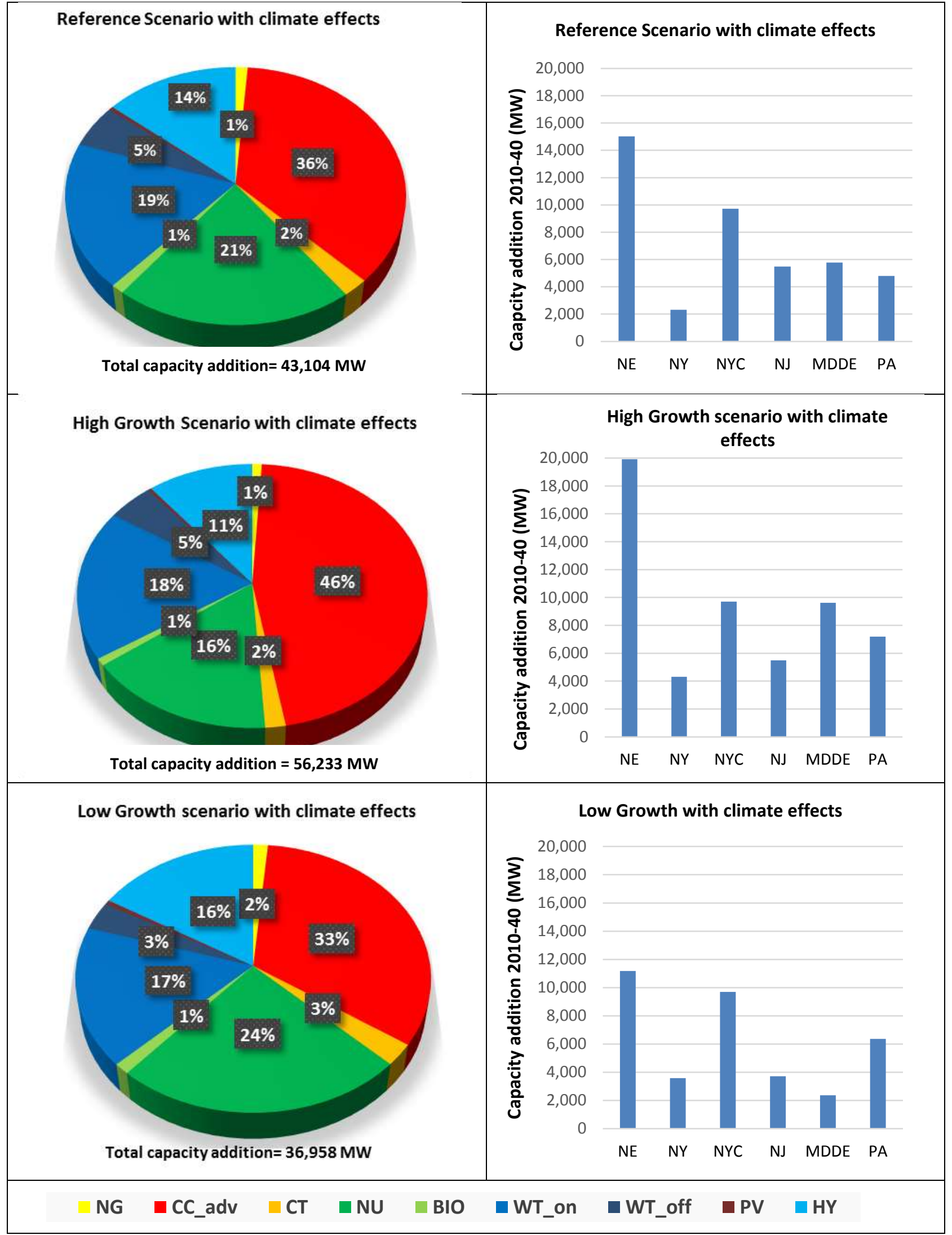


Figure 9: Average wholesale price trends for New Jersey under different scenarios

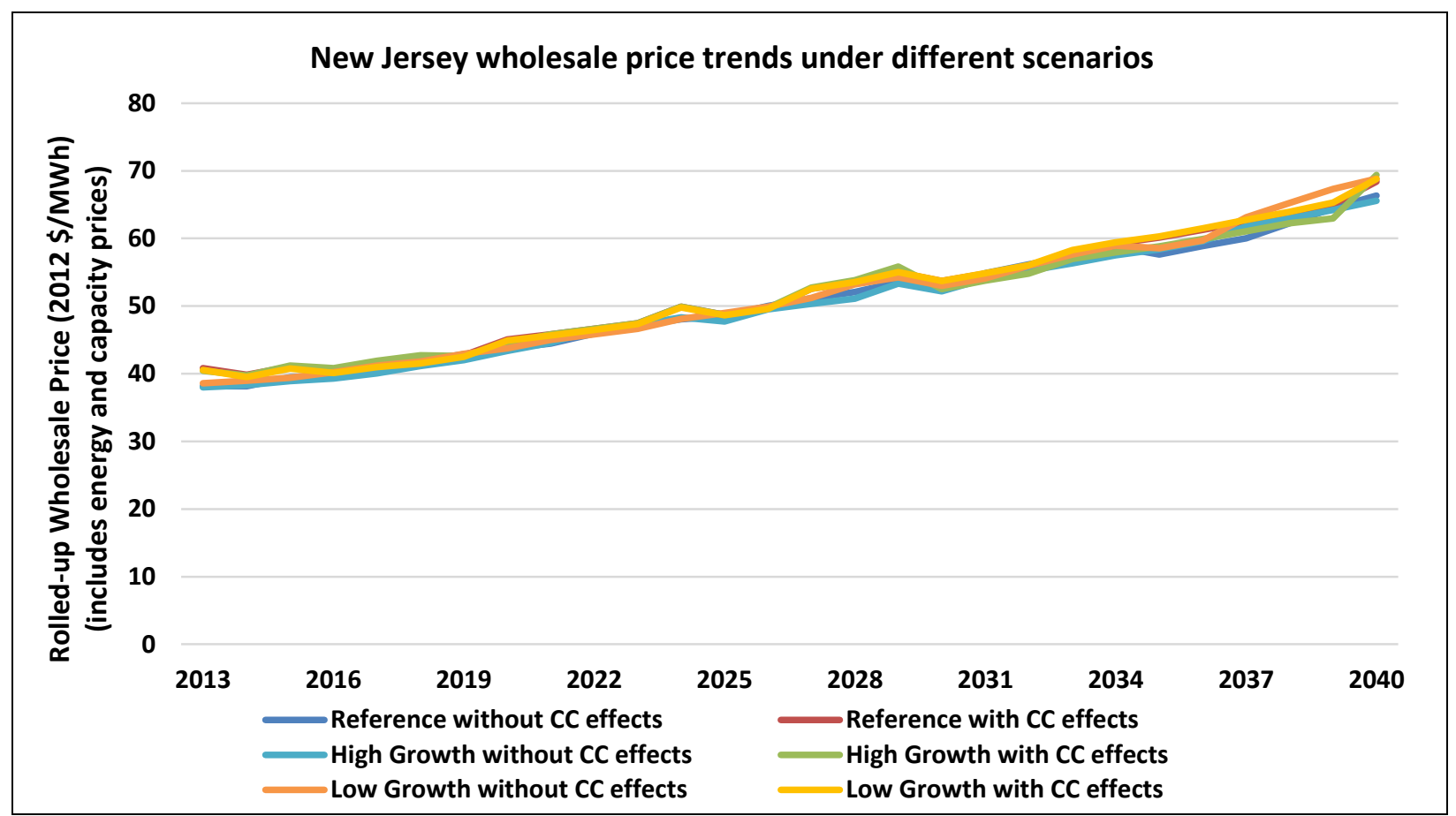

Note: Energy price is the dual variable of the energy constraint in the model (see Rau (2003) for theory and formulation behind dual prices). This energy price is weighted by the seasonal demand to get the energy component of the annual wholesale price. The capacity price is based on the dual variable of the capacity constraint in the model. The whole of Northeast region is assigned a uniform capacity price (\$/MW-year) for the intervening years based on the average dual capacity values for all subregions. 
Figure 10: Wholesale and Retail ratepayer impact for New Jersey customers under different scenarios

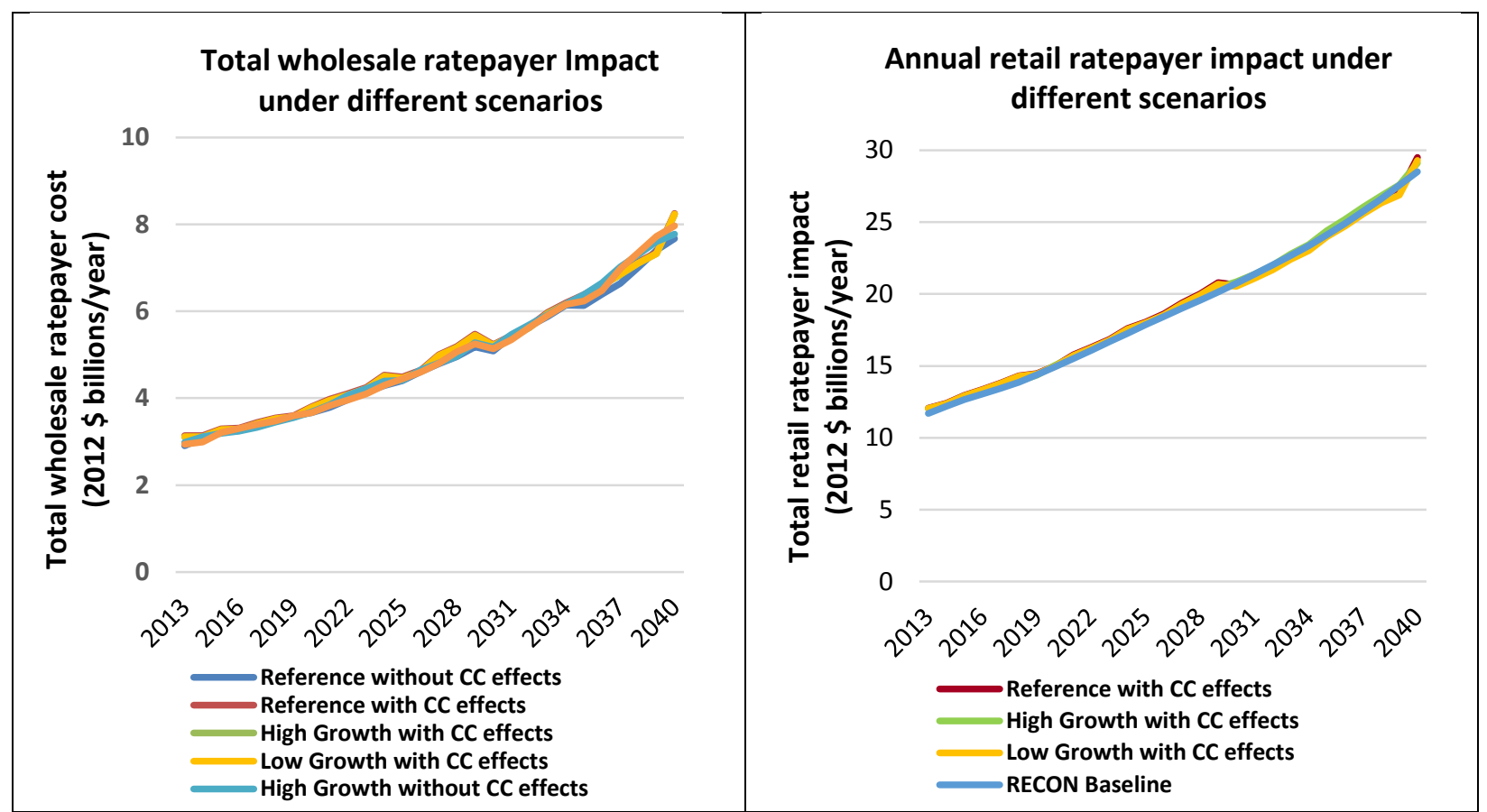

Note: The wholesale ratepayer impact is computed as the product of the rolled-up wholesale price and demand for a given year in New Jersey (and using annual retail prices for retail ratepayer impact). Since the wholesale component of electricity is only around $40-50 \%$ of the final retail prices, the fluctuations are not apparent in the final ratepayer impact graphs. 
Figure 11: Retail Price trends for New Jersey under different scenarios

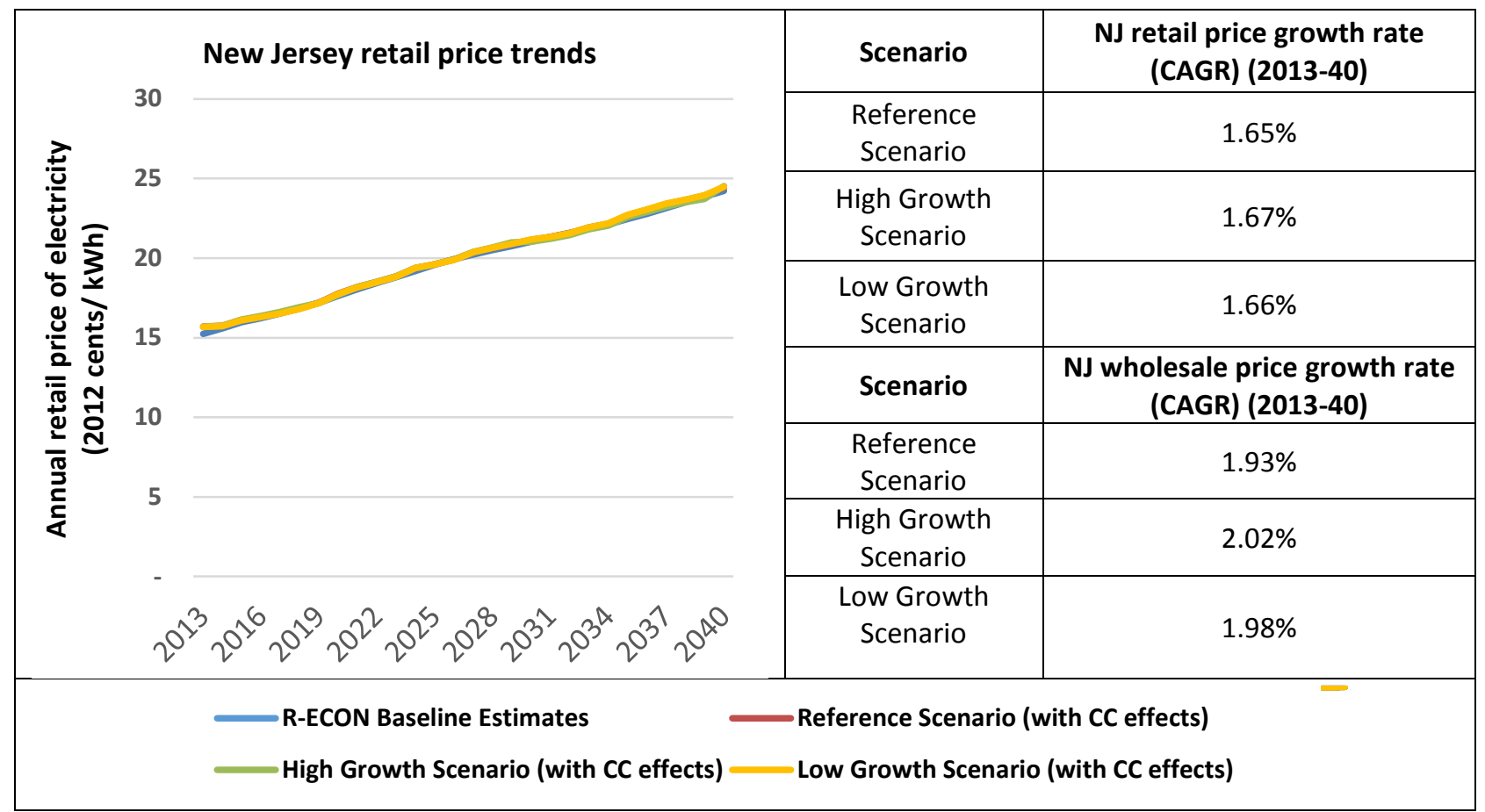

Note: Retail prices are usually expressed in cents/kWh (i.e. $100 \$ / \mathrm{MWh}$ is 10 cents/kWh). The retail price trends are based on the R/ECON Baseline input. The new set of retail prices, labeled as "coupled" prices, incorporates the premium of climate change effects on the wholesale component of the retail price. The wholesale component is about $40-50 \%$ of the final retail price for New Jersey (CEEEP, 2011: pp. 10-19). We do not estimate the climate effects on other components of the final retail price (like distribution, Federal \& state taxes, regulation costs etc.).

CAGR-Compound Average Growth Rate 
Figure 12: Differences in wholesale and retail ratepayer impact under different scenario themes

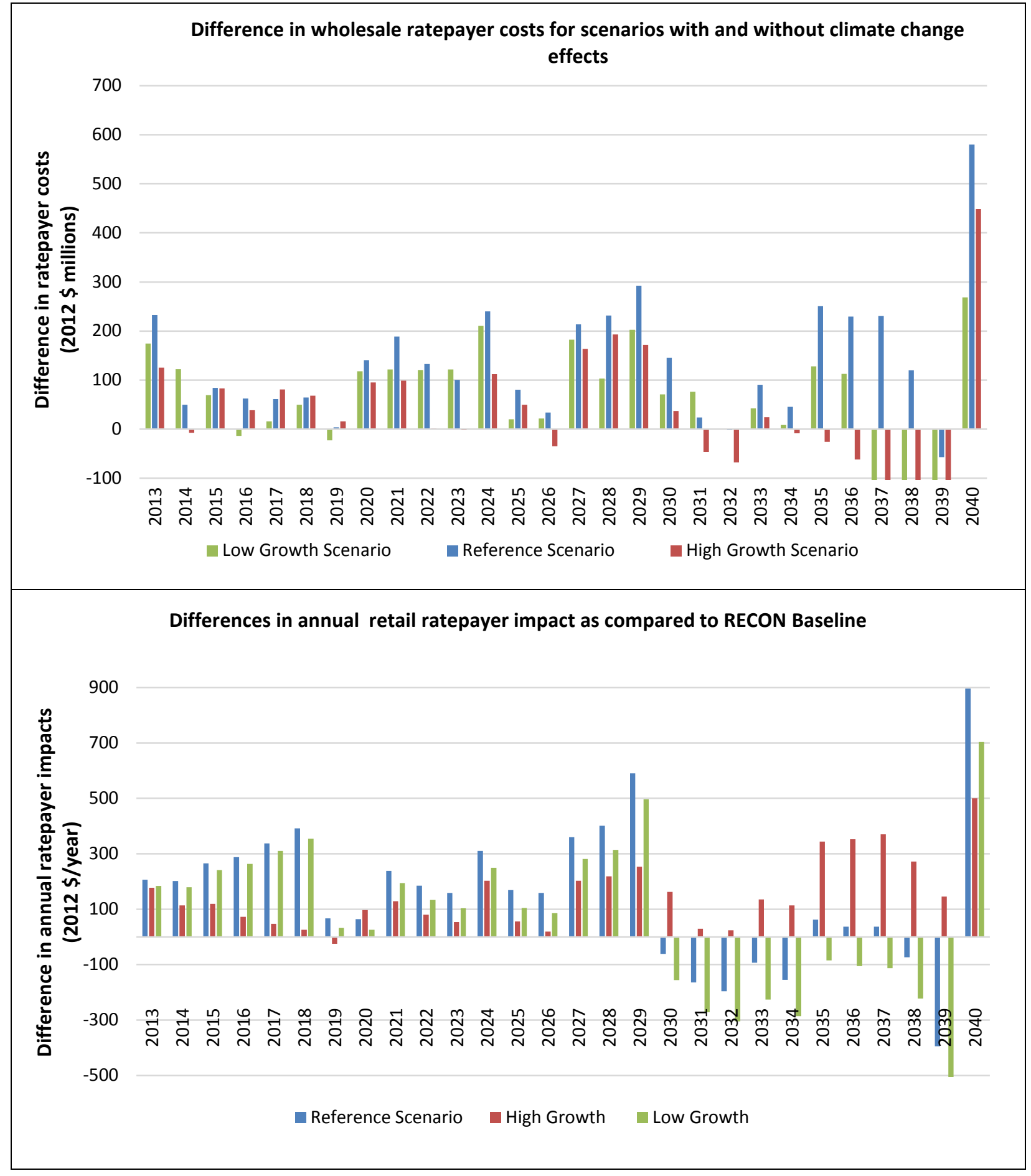


Figure 13: Differences in wholesale and retail prices under different scenario themes

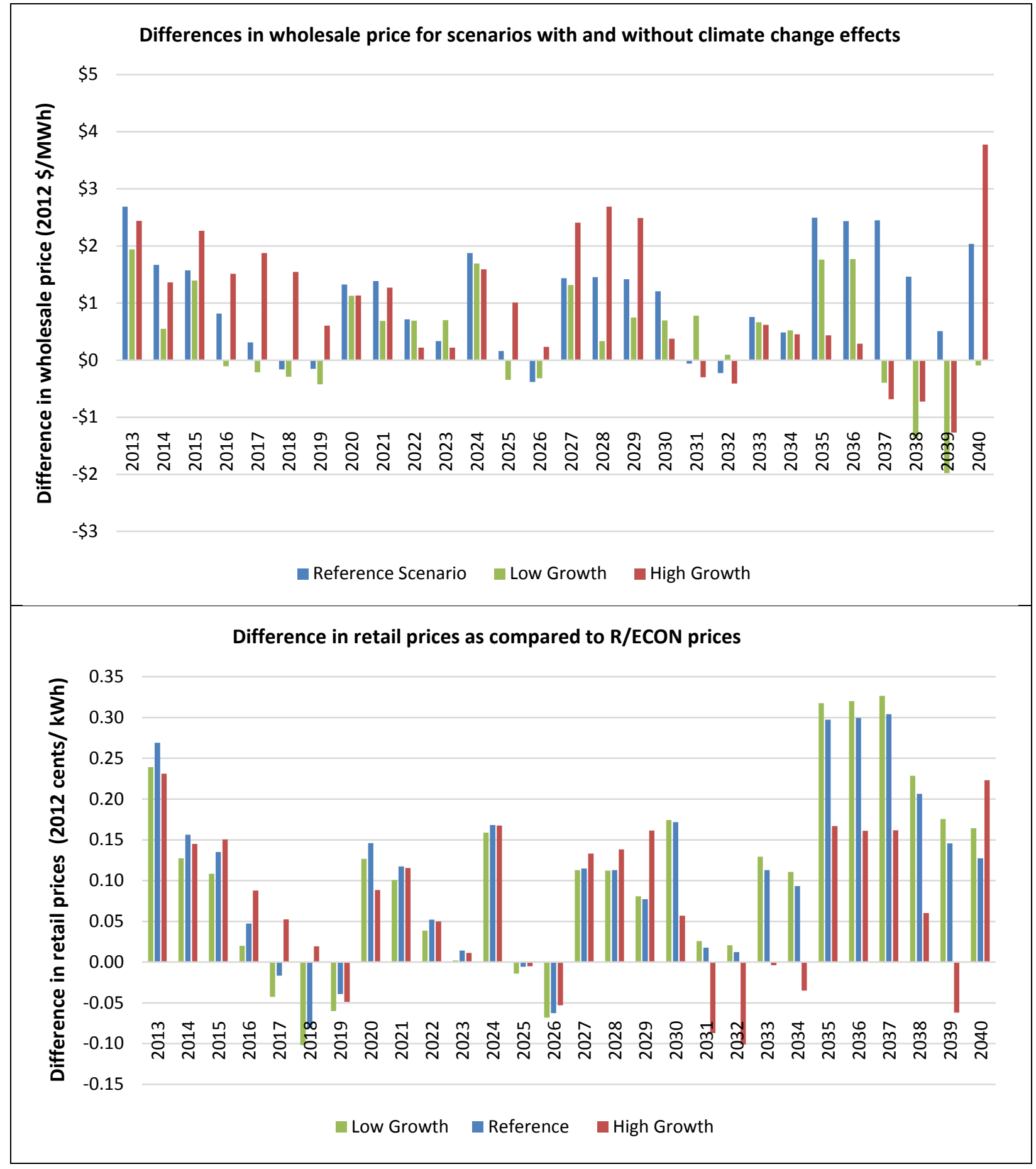


Table 1: A summary of recent peer reviewed studies using a GEM/CEM for extended policy analysis

\begin{tabular}{|c|c|c|}
\hline Study & Key policy implication studied & Modeling Approach \\
\hline Jaglom et al., [10] & $\begin{array}{l}\text { Modeling the impact of rising temperature } \\
\text { on the U.S power sector }\end{array}$ & $\begin{array}{l}\text { Uses EPA-ICF Consulting's Integrated } \\
\text { Planning Model (IPM), a dispatch and } \\
\text { capacity expansion model, to analyze the } \\
\text { impacts in terms of supply costs, } \\
\text { electricity prices, } \mathrm{CO}_{2} \text { emissions and } \\
\text { energy expenditures. }\end{array}$ \\
\hline Mai et al., [42] & $\begin{array}{l}\text { Modeling a high renewable electricity } \\
\text { penetration in the US }\end{array}$ & $\begin{array}{l}\text { Uses NREL's Regional Energy Deployment } \\
\text { System (REEDS) (a linear cost optimization } \\
\text { model), to study the capacity expansion } \\
\text { under a high renewable energy mix }\end{array}$ \\
\hline Logan et al., [41] & $\begin{array}{l}\text { Modeling natural gas scenarios for the U.S } \\
\text { power sector }\end{array}$ & $\begin{array}{l}\text { Uses NREL's REEDS, to study the future } \\
\text { trends in capacity expansion under } \\
\text { different natural gas price scenarios }\end{array}$ \\
\hline Webster et al., [40] & $\begin{array}{l}\text { Water- } \mathrm{CO}_{2} \text { emissions tradeoff in } \\
\text { generation expansion planning }\end{array}$ & $\begin{array}{l}\text { Uses a mixed integer linear program for } \\
\text { Texas ERCOT region for the year } 2050\end{array}$ \\
\hline Hu and Jewell, [43] & $\begin{array}{l}\text { Generation expansion with integration of } \\
\text { variable renewables and bulk energy } \\
\text { storage systems (modeled as an virtual } \\
\text { transmission line between time periods) }\end{array}$ & $\begin{array}{l}\text { Uses an optimal power flow (OPF) based } \\
\text { multi-period linear optimization model for } \\
\text { a test bus }\end{array}$ \\
\hline Clemmer et al., [8] & $\begin{array}{l}\text { Modeling low-carbon electricity futures to } \\
\text { study the impacts on water use }\end{array}$ & $\begin{array}{l}\text { Uses NREL's REEDS to model a range of } \\
\text { low-carbon scenarios for the U.S }\end{array}$ \\
\hline Fripp, [7] & $\begin{array}{l}\text { Generation expansion planning with large } \\
\text { scale penetration of renewables }\end{array}$ & $\begin{array}{l}\text { Uses a multi-period stochastic linear } \\
\text { programming model (called SWITCH) for } \\
\text { California (2012-2027) }\end{array}$ \\
\hline Bird et al., [47] & $\begin{array}{l}\text { Impact of renewable portfolio } \\
\text { standards(RPS) and cap-and-trade on U.S } \\
\text { electricity sector }\end{array}$ & $\begin{array}{l}\text { Uses NREL's REEDS to model a range of } \\
\text { policy scenarios for the U.S }\end{array}$ \\
\hline Chen et al., [39] & $\begin{array}{l}\text { Generation expansion planning towards a } \\
\text { low-carbon economy }\end{array}$ & $\begin{array}{l}\text { Uses a linear supply-side cost optimization } \\
\text { for China from } 2011-30 \text { with carbon costs } \\
\text { imposed on fossil-fuel generation }\end{array}$ \\
\hline Lucena et al., [11] & $\begin{array}{l}\text { Generation expansion planning for Brazil } \\
\text { under different climate change scenarios } \\
\text { (using downscaled climate projections) }\end{array}$ & $\begin{array}{l}\text { Uses a long-term optimization model } \\
\text { (called MEAD-MESSAGE) to examine the } \\
\text { possible adaptation pathways for Brazil }\end{array}$ \\
\hline Linares et al, [36] & $\begin{array}{l}\text { Incorporating oligopoly, } \mathrm{CO}_{2} \text { emissions } \\
\text { trading and green certificates into } \\
\text { generation expansion model }\end{array}$ & $\begin{array}{l}\text { Formulates a Mixed Complementarity } \\
\text { Problem (MCP) for each supply-side firm/ } \\
\text { generating technology and solved for } \\
\text { Spain }\end{array}$ \\
\hline Yu [44] & $\begin{array}{l}\text { Impact of charging profile of plug-in } \\
\text { hybrid vehicles (PHEV) on generation } \\
\text { expansion }\end{array}$ & $\begin{array}{l}\text { Uses EIA's National Energy Modeling } \\
\text { System (NEMS) equilibrium model to } \\
\text { project the capacity expansion for the U.S } \\
\text { under different scenarios till } 2030\end{array}$ \\
\hline
\end{tabular}


Table 2: Key input characteristics of generation technologies (for the starting year 2010) ${ }^{1,2}$

\begin{tabular}{|c|c|c|c|c|c|c|c|c|c|c|}
\hline \multirow[t]{2}{*}{ Type } & \multirow[t]{2}{*}{$\begin{array}{c}\text { Availability } \\
\text { Factor }\end{array}$} & \multirow{2}{*}{\multicolumn{2}{|c|}{$\begin{array}{c}\text { Overnight } \\
\text { Investment Cost } \\
(2012 \$ / \mathrm{kW})\end{array}$}} & \multicolumn{3}{|c|}{$\begin{array}{l}\text { Fixed Operating \& } \\
\text { Maintenance Cost } \\
\text { (2012 \$/kW-year) }\end{array}$} & \multirow[t]{2}{*}{$\begin{array}{c}\text { Variable O\&M } \\
\text { Costs } \\
\text { (2012 \$/MWh) }\end{array}$} & \multirow[t]{2}{*}{\begin{tabular}{|c|} 
Fuel Costs \\
(2012 \$/MMBTU) \\
(in 2010)
\end{tabular}} & \multicolumn{2}{|c|}{$\begin{array}{l}\text { Heat Rate } \\
\text { (BTU/kWh) }\end{array}$} \\
\hline & & & & Existing & & $w$ & & & Existing & New \\
\hline Coal & 0.75 & $\$$ & 3,246 & $\$ \quad 48.2$ & $\$$ & 37.8 & $\$ \quad 4.47$ & $\$ 2.39$ & 10,415 & 8,800 \\
\hline Advanced Coal (IGCC) & 0.85 & $\$$ & 4,400 & - & $\$$ & 37.8 & $\$ 7.22$ & $\$ \quad 2.39$ & -1 & 8,700 \\
\hline Advanced Coal with CCS & 0.85 & $\$$ & 6,599 & - & $\$$ & 80.5 & $\$ 8.45$ & $\$ \quad 2.39$ & - & 8,700 \\
\hline Combined Cycle(NG) & 0.80 & $\$$ & 917 & $\$ 29.7$ & $\$$ & 13.2 & $\$ \quad 3.60$ & $\$ 3.44$ & 8,185 & 7,050 \\
\hline Advanced CC & 0.87 & $\$$ & 1,023 & - & $\$$ & 15.4 & $\$ \quad 3.27$ & $\$ \quad 3.44$ & - & 6,430 \\
\hline CC with CCS & 0.87 & $\$$ & 2,095 & - & $\$$ & 31.8 & $\$ 6.78$ & $\$ \quad 3.44$ & - & 7,525 \\
\hline Combustion Turbine & 0.90 & $\$$ & 973 & $\begin{array}{ll}\$ & 6.7\end{array}$ & $\$$ & 7.3 & $\$ 15.45$ & $\$ 23.79 / \$ 3.44$ & 10.984 & 10,850 \\
\hline Advanced CT & 0.90 & $\$$ & 676 & - & $\$$ & 7.1 & $\$ 10.37$ & $\$ \quad 3.44$ & - & 10,850 \\
\hline Nuclear & 0.90 & $\$$ & 5,530 & $\$ 112.8$ & $\$$ & 93.3 & $\$ \quad 2.14$ & 5 & - & \\
\hline Geothermal & 0.92 & $\$$ & 4,362 & $\$ \quad 89.8$ & $\$$ & 100.0 & - & - & -1 & - \\
\hline Biomass (BFB) & 0.83 & $\$$ & 4,144 & $\$ 120.6$ & $\$$ & 105.8 & $\$ 5.25$ & $\$ 2.32$ & 13,500 & 13,500 \\
\hline On-shore Wind & 0.30 & $\$$ & 2,213 & $\$ \quad 34.2$ & $\$$ & 38.5 & - & - & - & - \\
\hline Off-shore Wind & 0.37 & $\$$ & 6,230 & & $\$$ & 74.0 & - & - & - & - \\
\hline Solar PV & 0.15 & $\$$ & 4,183 & $\$ \quad 14.6$ & $\$$ & 27.7 & - & - & - & - \\
\hline Solar Thermal & 0.20 & $\$$ & 5,067 & & $\$$ & 67.2 & - & - & - & - \\
\hline Hydro & 0.52 & $\$$ & 2,936 & $\$ 14.2$ & $\$$ & 14.1 & & & - & \\
\hline
\end{tabular}

${ }^{1}$ Availability factors are based on NREL [24]. All cost assumptions are based on EIA's Annual Energy Outlook Report [23, 48]. Also see [25] for average heat rate estimates.

${ }^{2}$ IGCC-Integrated Gasified Combined Cycle (IGCC); NG-Natural gas based combined cycles and steam turbines; CCS- Carbon capture and sequestration; BFBBubbling Fluidized Bed Boiler; CT- Combustion Turbine; PV-Photovoltaic 
Table 3: Existing generation portfolio (in MW) for the sub-regions in the Northeast region for $\mathbf{2 0 1 0 ^ { 1 }}$

\begin{tabular}{|c|c|c|c|c|c|c|c|c|c|c|}
\hline Capacity in MW & Coal & $\begin{array}{l}\text { Combined Cycle } \\
\text { \& NG Steam } \\
\text { Turbines }\end{array}$ & $\begin{array}{l}\text { Combustion } \\
\text { Turbine }\end{array}$ & Nuclear & $\begin{array}{l}\text { Geothe } \\
\text { rmal }\end{array}$ & Biomass & $\begin{array}{l}\text { On-shore } \\
\text { Wind }\end{array}$ & $\begin{array}{l}\text { Solar } \\
\text { PV }\end{array}$ & Hydro & $\begin{array}{c}\text { Regional } \\
\text { Total } \\
\text { (MW) }\end{array}$ \\
\hline New England & 2,855 & 17,648 & 2,244 & 4,654 & 5 & 830 & 277 & 5 & 3,477 & 31,995 \\
\hline New York State & 2,683 & 9,064 & 1,242 & 3,182 & 5 & 205 & 1,273 & 23 & 5,554 & 23,231 \\
\hline New York City & - & 10,599 & 4,755 & 2,037 & - & 240 & - & 20 & - & 17,651 \\
\hline New Jersey & 2,036 & 10,243 & 1,395 & 4,060 & - & 276 & 8 & 28 & 410 & 18,456 \\
\hline Maryland- Delaware & 5,940 & 3,440 & 3,955 & 1,705 & - & 12 & 72 & 2 & 590 & 15,716 \\
\hline Pennsylvania & 18,481 & 9,415 & 4,633 & 9,540 & - & 525 & 700 & 10 & 2,268 & 45,572 \\
\hline $\begin{array}{c}\text { Technology-wise } \\
\text { Total (MW) }\end{array}$ & 31,995 & 60,409 & 18,224 & 25,178 & 10 & 2,088 & 2,330 & 88 & 12,299 & 152,621 \\
\hline
\end{tabular}

${ }^{1}$ EIA-AEO [23]. 